\title{
Combustion Flame Spray of CoNiCrAlY \& YSZ Coatings
}

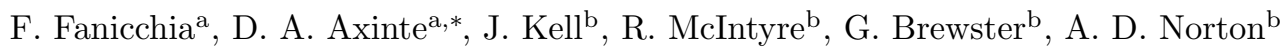 \\ ${ }^{a}$ UTC in Manufacturing and On-Wing Technology, Faculty of Engineering, University of Nottingham, NG7 2RD, UK \\ ${ }^{b}$ Repair Technology, Rolls-Royce plc, United Kingdom
}

\begin{abstract}
The properties of CoNiCrAlY and $\sim 7-8 \%$ YSZ layers, used as thermal barrier coatings (TBC) to protect hot gas paths of power generation and aerospace gas turbines, that have been deposited through the Combustion Flame Spray (CFS) process, are assessed and compared to coatings of the same materials deposited through Atmospheric Plasma Spray (APS). Fuel-to-oxygen equivalence ratio, combustion and carrier gases flows, torch standoff distance and powder feed rate values have been varied during the CFS tests in order to assess their effect on microstructural characteristics, i.e. thickness, total porosity, oxide level and microhardness. Results show that, in CFS-deposited coatings, although a higher content of oxide strings and porosity is observed compared to APS, also comparable phase transformations and a higher thermal cyclic lifetime can be achieved with an appropriate tuning of the deposition parameters. Thus, the study demonstrates the excellent capability of the CFS process in depositing thermal barrier coating systems, providing a viable alternative deposition technology for this class of materials at significant hardware simplicity. As the CFS setup has a simple design, this research stimulates a miniaturization concept of the combustion flame spray torch for allowing its deployment into highly restricted workspaces.
\end{abstract}

Keywords: Thermal Spray, Combustion Flame Spray, Atmospheric Plasma Spray, Thermal Barrier Coating, CoNiCrAlY bondcoat, Yttria Stabilised Zirconia YSZ topcoat

\section{Introduction}

Thermal barrier coatings (TBC), a class of materials of engineered properties, are widely used in several industrial environments (marine, aerospace, nuclear, etc.) to protect components having to withstand harsh thermo-mechanical conditions [1. In gas turbines, components in the hot gas paths are often exposed to higher temperatures than their melting point $\left(T>T_{m}\right)$. TBC, thanks to their characteristic multilayer structure are able to considerably reduce the temperature at contact with the parent component material and protect it from oxidation, thus improving its overall lifetime. Although widespread research in this field has brought to the development of several material compositions, due to their excellent thermal protection properties most of the TBC used in industry real-life applications are focused around two layers: a first metallic MCrAlY $(\mathrm{M}=\mathrm{Co}, \mathrm{Ni})$ bondcoat applied on top of the parent component material and a second ceramic $\mathrm{X} \%$ $\mathrm{Y}_{2} \mathrm{O}_{3}$ stabilized $\mathrm{ZrO}_{2}$ (or simply X-YSZ, $\mathrm{X}=7-8 \%$ ) topcoat layer. In a complete TBC system the bondcoat layer is applied onto the parent component material and acts as a reservoir of aluminum, which reacts with the atmospheric oxygen to generate a slow growing $\mathrm{Al}_{2} \mathrm{O}_{3}$ protective Thermally Grown Oxide (TGO) layer. The

\footnotetext{
* Correspondingauthor

Email address: Dragos.Axinte@nottingham.ac.uk (D. Axinte)
}

high melting point topcoat, applied onto the bondcoat layer, is responsible for the thermal protection and thus a specific degree of its intrinsic porosity has been proven beneficial [1, 2].

Currently, thermal spray of solid powder particles is widely used to deposit TBC materials. This technique relies on the energy provided by an energetic jet stream to melt the feedstock material and direct it towards the component surface, where the particles plastically deform and overlap, generating a coating. The final properties (e.g. mechanical, thermal transport, etc.) of a thermally sprayed layer depend on its microstructure which in turn is driven by velocity, temperature and oxidation properties of in-flight particles before impact 2]. In particular, it is widely recognised that particle melting is a fundamental requirement for a strong coating adhesion and hardness. In a simplified approach, i.e. by neglecting thermal conduction within the particle and oxidative phenomena, it is possible to define the necessary condition to melt the particle as 3 :

$$
\begin{gathered}
\int_{0}^{\tau} Q_{i n t} \cdot d t>Q_{M} \\
Q_{\text {int }}=h\left(\pi d_{p}^{2}\right)\left(T_{\infty}-T_{p}\right)-\left(\pi d_{p}^{2}\right) \epsilon \sigma_{s}\left(T_{p}^{4}-T_{a}^{4}\right)
\end{gathered}
$$




$$
Q_{M}=\frac{4}{3} \pi \rho_{p} d_{p}^{3}\left(C_{p}\left(T_{m}-T_{0}\right)+L_{m}\right) \quad[J]
$$

where $\tau$ is the particle in-flight dwell time, $d_{p}, \rho_{p}$ and $C_{p}$ are the particle diameter, density and specific heat in solid state respectively, $h$ is the convective heat transfer coefficient, $T_{\infty}$ is the flame temperature at the particle surface, $\epsilon$ is the particle emissivity, $\sigma_{s}$ is the Stefan-Boltzmann constant, $T_{p}$ and $T_{a}$ are the temperature of the particle and surroundings, and $T_{m}, T_{0}$ and $L_{m}$ are the particle melting and initial temperature and latent heat of fusion respectively. Eq. 1 states that, a particle injected within a thermal jet will reach a molten state if the heat transferred $\left(Q_{i n t}\right)$ during a flight lasting $\tau$ is higher than the heat required to melt the particle $\left(Q_{M}\right)$. The heat exchanged (Eq. 22) contains two terms, the convective jet fluid/particle heat transfer (energy intake term) and the radiative loss to the environment (energy loss term). Besides being dependent on the particle dimension (through the surface area term $\pi d_{p}^{2}$ ), $Q_{\text {int }}$ results time dependent due to the spatial variation the jet temperature $T_{\infty}$ and particle temperature $T_{p}$. The melting heat (Eq. 3 is a property that depends on the shape/size (through $d_{p}$ ), material composition (through $\rho_{p}, C_{p}, T_{m}$ and $L_{m}$ ) and can be therefore considered constant for a specific particle morphology. The dwell time $\tau$ in Eq. 1 represents the time spent by the particle in flight before reaching the substrate. Hence, in a first approximation, by defining the in-flight distance with a standoff distance parameter $(S O D)$ the dwell time can be evaluated as $\tau=\frac{S O D}{v_{p}}, v_{p}$ being the particle velocity. This latter quantity, the particle velocity, dependson a number of factors, among which carrier gas and combustion gases flows, particle density and diameter are the most relevant. In order to account for thermal and mechanical interactions between the jet and particle stream, the powder-to-jet mass flow ratio parameter $M_{F}$ can be defined:

$$
M_{F}=\frac{M_{\text {powder }}}{M_{\text {jet stream }}}
$$

where $M_{\text {jetstream }}$ and $M_{\text {powder }}(\mathrm{g} / \mathrm{min})$ are the mass flow of the gases composing the jet stream and the powder feed rate respectively. It is generally considered that if a value of $M_{F}$ exceeding $4 \%$ is obtained at a given combination of deposition parameters, the jet stream thermal and flow properties cannot be considered independent from the powder stream anymore (also called "loading effect"). Particle in-flight oxidation is a further effect observed in metallic CoNiCrAlY materials. Assuming single oxide species, oxidation kinetics can be described by an Arrhenius law of the type:

$$
k=A \cdot e^{-\frac{E_{A}}{k_{B} T_{p}}}
$$

where $k$ is the reaction rate constant, $A$ is the preexponential factor (slightly temperature-dependent), $E_{A}$ is the oxidation reaction activation energy, $k_{B}$ is the Boltzmann constant and $T_{p}$ is again particle temperature. The reaction is thus facilitated by higher particle temperatures reached in-flight.

In practice, depending on the in-flight conditions experienced by the particles, resulting thermally sprayed coatings are characterised by a given degree of porosity, generated by the incomplete overlap of impacting splats, unmolten particles, created by in flight powder not gaining sufficient heat for melting, and in metallic materials, oxide strings. An analysis and understanding of the abovementioned properties for the thermal spray system under analysis is therefore of fundamental importance if specific coating performance has to be achieved.

Currently, among the thermal spray technologies, Atmospheric Plasma Spray (APS) is the most widely used. Plasma jets of 8.000-14.000 K and particles speeds in the range $100-300 \mathrm{~m} / \mathrm{s}$ are generally achieved, allowing a wide range of materials to be melted including highlyrefractory ceramic materials. As a general rule, metallic MCrAlY bondcoats deposited through this technique, always show the presence of oxide strings $(2-15 \%)$ and porosity $(4-10 \%)$ [4, 5, 6, this latter property is also found in ceramic YSZ topcoats (5-25\%) along with microcracking [5, 7].

Significant advantages in terms hardware simplification could be attained by the application of TBC materials through the Combustion Flame Spray (CFS) technology. In this case, the combustion between premixed oxygen and acetylene gases provides the energetic jet stream. Flame temperatures up to $3.400 \mathrm{~K}$ and particles velocities below $100 \mathrm{~m} / \mathrm{s}$ are generally achieved [2]. The lower temperature of the jet stream compared to APS is widely considered hindering the deposition of refractory ceramic materials, and in fact maximum temperature reached by in-flight particles for these systems are commonly reported to be $\mathrm{T}_{p}=0.7 \mathrm{~T}_{g}$ to $0.8 \mathrm{~T}_{g}$, where $\mathrm{T}_{g}$ is the flame temperature (2300 K to $2700 \mathrm{~K}$ for Tp respectively) [2, 8. A fundamental parameter in CFS is thus represented by the acetylene-to-oxygen equivalence ratio $(\Phi)$, defined by the mass flow ratio of actual acetylene-to-oxygen ratio to the stoichiometric value of the same quantity, or $\Phi=m_{C_{2} \mathrm{H}_{2}} / m_{\mathrm{O}_{2}} /\left(m_{C_{2} \mathrm{H}_{2}} / m_{\mathrm{O}_{2}}\right)_{s t}$, where the subscript $m$ refers to mass and st to stoichiometric. This latter value defines the flame temperature profile, with maximum values of $3.400 \mathrm{~K}$ reached for $\Phi \sim 1.19$. The amount of oxygen present in the flame, and consequently its oxidative properties, can also be tailored by a change in $\Phi$ : an increase in the amount of acetylene corresponds to $\Phi>1$ and thus a decrease in the oxygen flow reaching the in-flight particles. Despite a lower thermal content compared to APS, the lower speed experienced by the in-flight particles compared to APS technology could be exploited to increase the particles dwell time inside the jet, thus improving their temperature and obtaining a coating suitable for TBC applications. Moreover, CFS technology, 
with its highly simplified hardware compared to APS, could achieve smaller dimensions, offering the possibility to be utilised when repair works need to be performed to installations where limited access is permitted.

Published literature on CFS deposition of TBC materials was very scarce and limited in time until the 1970, when the APS technology started to gain ground in the thermal spray industry. Riley [10] seems to be first describing, in a very simplified approach and often lacking experimental details, the possibility to deposit zirconia- and aluminabased coatings via rod and powder CFS for aerospace applications, reporting a total porosity of $8-10 \%$. In the same vein, Ault 11 details on metallographic and thermal fatigue properties of calcia stabilized zirconia $\left(\mathrm{CaZrO}_{3}\right)$ and zirconium coatings produced through rod flame spray, describing measured values of $\sim 7 \%$. Some years later, Grisaffe [12, in his review on state-of-the-art thermal spray technologies, describes an ongoing transition from CFS- to APS-sprayed ceramic coatings, caused by higher deposition throughputs given by the improved thermal content in the jet stream, despite noting a parallel increase in the cost of the technology. Although describing the possibility to spray ceramic materials for TBC applications, these early studies present several drawbacks. The lack of details in the data presented, including experimental setups/deposition parameters, analysis methods and quality of the optical microscopies makes difficult to extract useful information and compare the experimental outputs to state of the art APS-deposited TBC systems. To authors' knowledge, the only attempts in CFS deposition of TBC materials in recent times has been performed by Cano [13] and Gonzalez [14]. The former performed a microstructural analysis on CFS-sprayed $\mathrm{CaZrO}_{3}$ ceramic coatings against different gases equivalence ratios, reporting porosities levels of $12-15.7 \%$ at an acetylene to oxygen equivalence ratio of 1.1. Although showing potential for the technology in depositing TBC systems, the work lacks a comprehensive study on the effects that variation in deposition parameters and starting powder material morphology has on the quality of the coatings produced for both bondcoat and topcoat materials. More recently Gonzalez assessed the quality of $\mathrm{ZrO}_{2}-\mathrm{Al}_{2} \mathrm{O}_{3}$ and $\mathrm{ZrO}_{2}-\mathrm{CeO}_{2}$ ceramic and $\mathrm{Ni}-\mathrm{Al}-\mathrm{Mo}$ bondcoat multilayer CFS sprayed at different values of torch-to-substrate standoff distance. Reported porosities in the range 14.8-18\% at standoff distances of 75 to $125 \mathrm{~mm}$ for the ceramic coatings are consistent with the previous work, however, no analysis was reported in the case of bondcoat layer and other relevant deposition parameters, including feedstock powder morphology. Moreover, the lower melting point of the materials tested in the abovementioned studies: $\sim 2500^{\circ}\left(\mathrm{CaZrO}_{3}\right), \sim 2100^{\circ} \mathrm{C}\left(\mathrm{ZrO}_{2}-\mathrm{Al}_{2} \mathrm{O}_{3}\right)$ and $\sim 2400^{\circ} \mathrm{C}\left(\mathrm{ZrO}_{2}-\mathrm{CeO}_{2}\right)$ compared to ceramic topcoat used in engineering applications (e.g. $\sim 2700^{\circ} \mathrm{C}$ for $\mathrm{YSZ}$ ) makes the CFS deposition intrinsically less challenging. Thus, to the author's knowledge no study on deposition and microstructure optimisation of has yet been performed on combustion flame spraying of high melting point YSZ ceramic materials.

The aim of the present paper is therefore twofold: demonstrating the possibility to CFS deposit CoNiCrAlY bondcoats and high melting point $\sim 7-8 \%$ YSZ topcoats while further providing a deposition parameters selection guideline for TBC applications of these materials.

Microstructural features of deposited coatings, including porosity and oxide strings are quantified by using consistent methodologies and related to measured microhardness, in coatings sprayed through the two deposition methods. An extensive experimental analysis of the effect of deposition parameters including: powder morphology (size and shape), equivalence ratio, powder feed rate, carrier gas flow and torch-to-substrate standoff distance has been performed for the CFS-produced TBC to complete the lack of knowledge in literature data. The analysis is complemented by a final comparison in microstructure, crystallographic phases and thermal fatigue performance against, now, conventional APS-deposited coatings. The study is of key importance, as it confirms that coating attributes comparable (or even higher in case of thermal cycling) to APS-deposited systems can be obtained using CFS technology, setting a viable cost-effective process for TBC deposition over small areas (e.g. for in-situ repair of intricate installations without the need of their disassembly).

\section{Materials \& Methods}

\subsection{Materials \& Setup}

Three commercially available Co-32Ni-21Cr-8Al-0.5Y (Amdry 995C, Amperit 415.001 and 415.063) and four $\sim 7$ 8\% YSZ (Metco 204F, Metco 6700, Amperit 827.054 and Amperit 831.054) powders were used for the CFS experiments, while Amdry 995C and Metco 204B-NS were used as bondcoat and topcoat materials respectively in APS deposition. The powder adopted in the current study, manufacturing method and nominal size distribution (as specified by the manufacturers), together with SEM micrographs are also reported in Tables 1 and 2, while thermal and physical properties for the same materials are summarised in Tab. 3. The Castodyn ${ }^{\circledR}$ TeroDyn 3000 oxyacetylene torch (Castolin-Eutectic ${ }^{\circledR}$ ) was employed for CFS while the F4-MB type torch (Oerlikon-Metco ${ }^{\circledR}$ ) was used for the APS sprayed coatings. Powder injection was performed via an automatic feeding system using argon as carrier gas and $50 \times 25 \times 3 \mathrm{~mm}^{3}$ mild steel specimens were used as substrates.

\subsection{Methodology}

A schematic of the CFS process is depicted in Fig. 1(a), where the deposition parameters, subdivided between those kept constant or specifically varied in this study are summarised in the inset. In this work, the ef- 

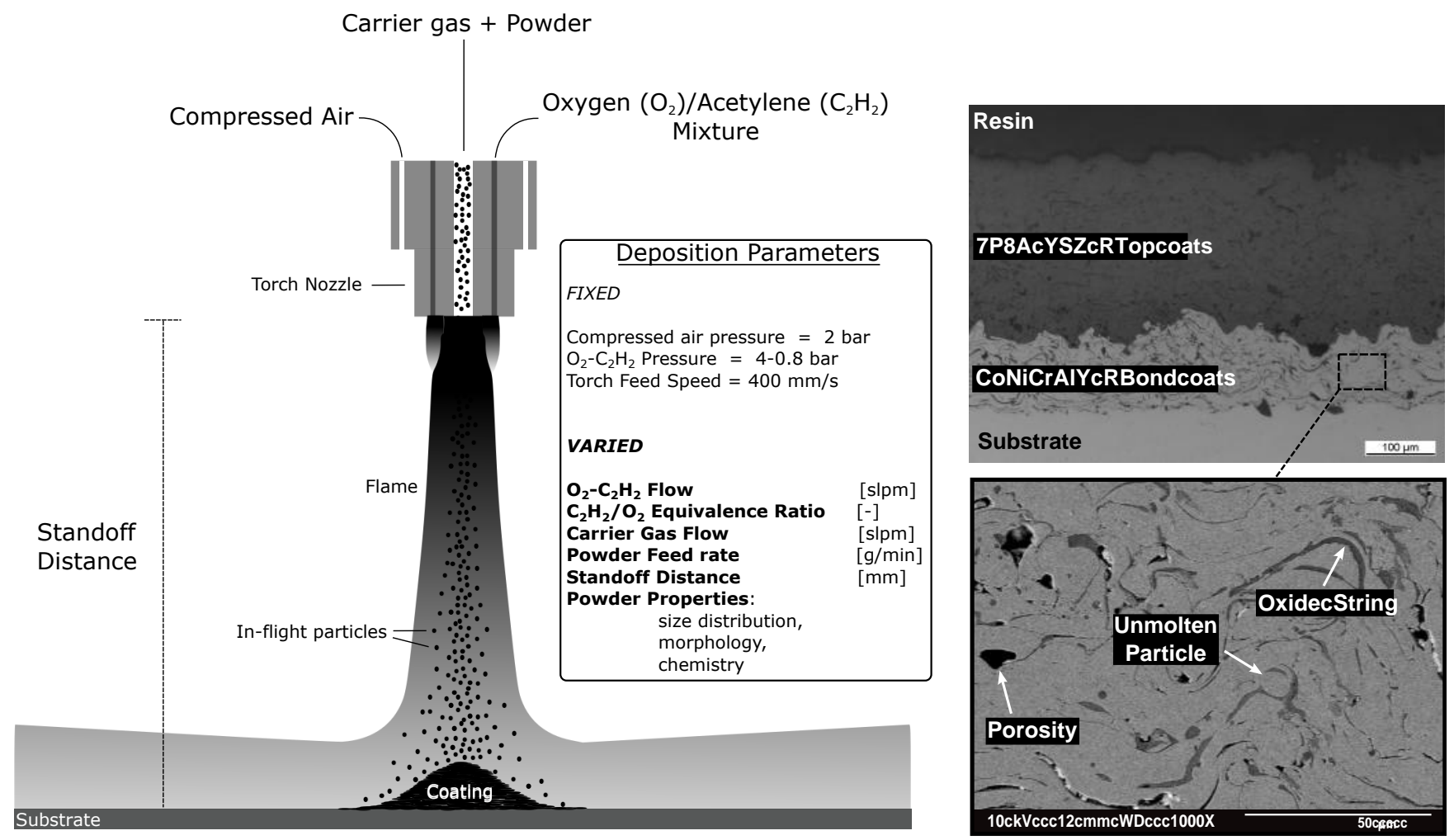

(a) CFS process principle, showing the deposition parmeters kept constant and varied in (b) Optical and SEM micrographs of a typical this study.

TBC coating produced in this study.

Figure 1: (a) Schematic of CFS principle, with fixed and varied deposition parameters specified and (b) optical (with highlighted SEM) micrograph of CFS-deposited TBC multilayer, showing relevant microstructural features.

Table 1: Name and properties of CoNiCrAlY and $~ 7-8 \%$ YSZ powders

\begin{tabular}{|c|c|c|c|}
\hline \# & $\begin{array}{l}\text { Powder Name } \\
\text { (Commercial) }\end{array}$ & $\begin{array}{l}\text { Manufacturing } \\
\text { Method }\end{array}$ & $\begin{array}{l}\text { Nominal Size } \\
\text { Distribution } \\
(\mu m)\end{array}$ \\
\hline \multicolumn{4}{|c|}{ CoNiCrAlY (CFS) } \\
\hline A & Amdry 995C & Gas Atomised & $-90+45$ \\
\hline B & Amperit 415.001 & Gas Atomised & $-45+22$ \\
\hline $\mathrm{C}$ & Amperit 415.063 & Gas Atomised & $-75+45$ \\
\hline \multicolumn{4}{|c|}{$\sim 7-8 \%$ YSZ (CFS) } \\
\hline $\mathrm{E}$ & Metco $204 \mathrm{~F}$ & HOSP & $-45+15$ \\
\hline $\mathrm{F}$ & Metco 6700 & Agglomerated & $-30+1$ \\
\hline G & Amperit 827.054 & $\begin{array}{l}\text { Agglomerated } \\
\text { \& Sintered }\end{array}$ & $-45+10$ \\
\hline $\mathrm{H}$ & Amperit 831.054 & $\begin{array}{l}\text { Plasma } \\
\text { Spheroidized }\end{array}$ & $-45+10$ \\
\hline \multicolumn{4}{|c|}{ CoNiCrAlY/ 7-8\%YSZ (APS) } \\
\hline A & Amdry 995C & Gas Atomised & $-90+45$ \\
\hline $\mathrm{D}$ & Metco 204B-NS & HOSP & $-75+45$ \\
\hline
\end{tabular}

fect of change in these latter quantities on CFS deposited coatings of CoNiCrAlY and $\sim 7-8 \%$ YSZ was assessed by analysing and comparing the resultant thickness, level of oxide, porosity and microhardness. For comparison purposes, APS-deposited TBC specimens were prepared based on standard parameters widely used in literature for the hardware and materials employed within this study
(Tab. 4). The measured microstructural properties were supported by optical (on coatings cross-sections) and SEM micrographs (of both coatings cross-sections and single splats) together with phase analysis via X-ray diffraction (XRD) in order to deeply characterise possible depositioninduced microstructure and phase modifications.

With regards to CoNiCrAlY deposition, three powders of different morphology but same chemical composition were tested each at three different levels of standoff distance. A neutral ( $\Phi=1$, corresponding to $\mathrm{O}_{2} / \mathrm{C}_{2} \mathrm{H}_{2}$ flows of $37.5 / 15 \mathrm{slpm}$ ) and a highly reducing equivalence ratio $\left(\Phi=2.65\right.$, corresponding to $\mathrm{O}_{2} / \mathrm{C}_{2} \mathrm{H}_{2}$ flows of $15 / 15.9$ slpm) were used in order to assess the effect of this parameter on the coating oxidation. Four powders of different morphology were employed during the deposition of $\sim 7$ $8 \%$ YSZ. All the deposition parameters were varied during this last set of tests and a standard CoNiCrAlY layer (deposition conditions as specimen BC5 in Tab. 5) was employed as bondcoat in all these specimens. A $\Phi=1.1$ value of the equivalence ratio $\left(\mathrm{O}_{2} / \mathrm{C}_{2} \mathrm{H}_{2}\right.$ flows of $34.1 / 15$ slpm) was maintained for these last set of tests in order to maximise the flame temperature [9]. Due to slight variations in powder feed rate caused by changes in carrier gas flow, its value was determined and adjusted before each test through mechanical control of the powder feeder disk. A standard rastering pattern, consisting of back- 
Table 2: SEM micrographs of CoNiCrAlY $~ 7-8 \%$ YSZ powders, showing differences in size and morphology.
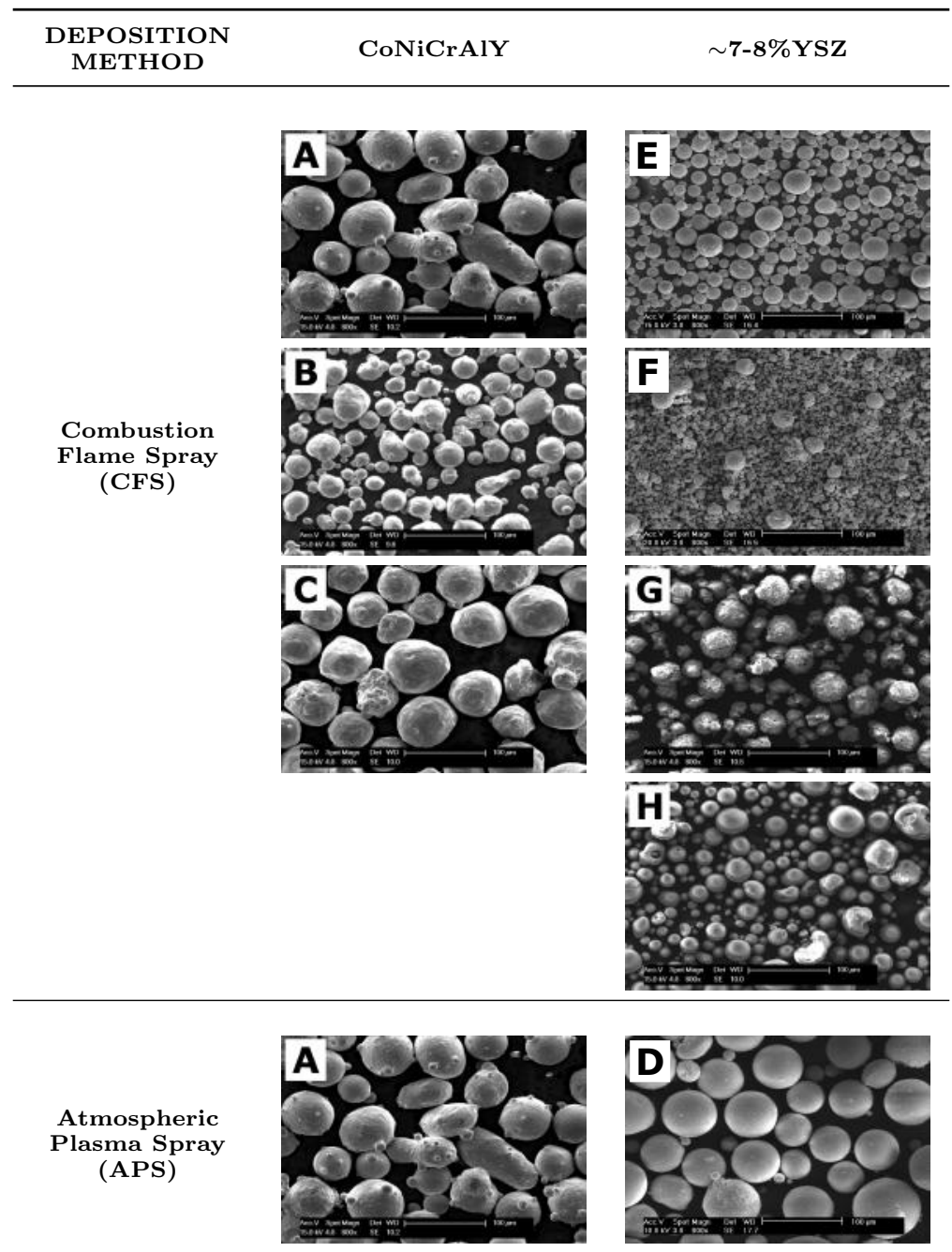

Table 3: Typical thermal and physical properties of the CoNiCrAlY and $\sim 7-8 \%$ YSZ powders.

\begin{tabular}{lll}
\hline & CoNiCrAlY $\mathbf{1 5}$ & $\sim 7$-8\%YSZ $[\mathbf{1 6}$ \\
\hline$\rho_{p}\left(\mathrm{~kg} / \mathrm{m}^{3}\right)$ & 7992 & 5890 \\
$T_{m}\left({ }^{\circ} \mathrm{C}\right)$ & 1380 & 2700 \\
$L_{m}(\mathrm{~kJ} / \mathrm{kg})$ & 293.7 & 710 \\
$C_{p}(\mathrm{~J} / \mathrm{kg} \cdot \mathrm{K})$ & 473 & 482 \\
\hline
\end{tabular}

and-forth torch movements at constant linear speed $(400$ $\mathrm{mm} / \mathrm{s}$ ) and $4 \mathrm{~mm}$ step size between the scan lines was used, and a constant number of cycles (defined by the number of times the whole substrate surface is covered by the torch) was adopted for each material: 15 (CoN$\mathrm{iCrAlY}$ ) and 23 ( 7-8\% YSZ). The adopted values were selected so that a uniform coating thickness, adequate for microstructure analysis could be obtained. Air pressure ( 2 bar) and oxygen/acetylene pressures ( 4 and 0.8 bar respectively) were selected from pre-optimisation trials (not reported) and kept fixed during all experiments. Three specimens per set of deposition conditions were produced
Table 4: APS spraying parameters used in this work.

\begin{tabular}{lll}
\hline Process Parameters & $\begin{array}{l}\text { Amdry } \\
\mathbf{9 9 5 C}\end{array}$ & $\begin{array}{l}\text { Metco } \\
\text { 204B-NS }\end{array}$ \\
\hline Primary Gas Type & $\mathrm{Ar}$ & $\mathrm{Ar}$ \\
Secondary Gas Type & $\mathrm{N}_{2}$ & $\mathrm{~N}_{2}$ \\
Primary Gas Flow Rate & $70-80$ & $60-70$ \\
$($ slpm) & & \\
Secondary Gas Flow Rate & $3-6$ & $8-10$ \\
$($ slpm) & & \\
Carrier Gas $($ slpm $)$ & $4-6$ & $3-6$ \\
Spray Distance $(\mathrm{mm})$ & $120-150$ & $120-150$ \\
Powder Feed Rate $(\mathrm{g} / \mathrm{min})$ & $30-40$ & $30-40$ \\
\hline
\end{tabular}

for reproducibility purposes. Substrates were prepared before deposition by degreasing with acetone and grit blasting with 20 mesh alumina grit in order to give a pre-coating surface roughness Ra $\sim 5 \mu \mathrm{m}$ as separately measured by a Talysurf PGI1240 contact profilometer. Single splats were obtained with both deposition technologies by spraying onto previously polished $(\mathrm{Ra} \sim 0.04 \mu \mathrm{m})$ and preheated $\left(\sim 400^{\circ} \mathrm{C}\right)$ substrates, placed onto a specifically designed 
Table 5: CFS spraying parameters and experimental microstructure results.

\begin{tabular}{|c|c|c|c|c|c|c|c|c|c|}
\hline Sample & $\begin{array}{l}\text { Powder } \\
\#\end{array}$ & $\begin{array}{l}\text { Standoff } \\
\text { Distance } \\
(\mathrm{mm})\end{array}$ & $\begin{array}{l}\text { Equivalence } \\
\text { Ratio } \phi^{a} \\
(-)\end{array}$ & $\begin{array}{l}\text { Powder } \\
\text { Feed Rate } \\
(\mathrm{g} / \mathrm{min})\end{array}$ & $\begin{array}{l}\text { Carrier } \\
\text { Gas Flow } \\
(\operatorname{slpm})^{b}\end{array}$ & $\begin{array}{l}\text { Thickness } \\
(\mu m)\end{array}$ & $\begin{array}{l}\text { Porosity } \\
(\text { area\%) }\end{array}$ & $\begin{array}{l}\text { Oxide } \\
\text { Strings } \\
(\text { area\%) }\end{array}$ & $\begin{array}{l}\mathbf{H K}_{0.3} \\
(-)\end{array}$ \\
\hline \multicolumn{10}{|c|}{ CoNiCrAlY } \\
\hline $\mathrm{BC} 0$ & A & 100 & 1 & 16 & 6 & $\mathbf{2 1 5} \pm 26$ & $\mathbf{2 . 4} \pm 0.5$ & $\mathbf{3 8 . 6} \pm 4$ & - \\
\hline $\mathrm{BC} 1$ & $\mathrm{~A}$ & 90 & 2.65 & 16 & 6 & $\mathbf{2 6 4} \pm 34$ & $\mathbf{3 . 3} \pm 0.8$ & $10.2 \pm 6$ & $\mathbf{3 2 7} \pm 34$ \\
\hline $\mathrm{BC} 2$ & A & 100 & 2.65 & 16 & 6 & $\mathbf{2 3 8} \pm 32$ & $4 \pm 1.2$ & $11.3 \pm 5$ & $308 \pm 25$ \\
\hline $\mathrm{BC} 3$ & A & 110 & 2.65 & 16 & 6 & $\mathbf{2 2 5} \pm 35$ & $4.4 \pm 1$ & $12.0 \pm 5$ & $\mathbf{3 1 5} \pm 38$ \\
\hline $\mathrm{BC} 4$ & B & 90 & 2.65 & 16 & 6 & $\mathbf{2 0 4} \pm 9$ & $1.8 \pm 0.5$ & $20.6 \pm 3$ & $\mathbf{2 9 8} \pm 26$ \\
\hline $\mathrm{BC} 5$ & B & 100 & 2.65 & 16 & 6 & $195 \pm 13$ & $\mathbf{2 . 1} \pm 0.7$ & $\mathbf{2 2 . 4} \pm 6$ & $\mathbf{2 8 3} \pm 35$ \\
\hline $\mathrm{BC} 6$ & B & 110 & 2.65 & 16 & 6 & $182 \pm 10$ & $\mathbf{2 . 3} \pm 0.6$ & $\mathbf{2 2 . 2} \pm 3$ & $\mathbf{2 7 5} \pm 28$ \\
\hline $\mathrm{BC} 7$ & $\mathrm{C}$ & 90 & 2.65 & 16 & 6 & $\mathbf{2 1 5} \pm 19$ & $\mathbf{2} \pm 0.5$ & $16.2 \pm 3$ & $\mathbf{2 9 3} \pm 35$ \\
\hline $\mathrm{BC} 8$ & $\mathrm{C}$ & 100 & 2.65 & 16 & 6 & $204 \pm 22$ & $\mathbf{2 . 4} \pm 0.5$ & $16.7 \pm 4$ & $\mathbf{3 0 1} \pm 32$ \\
\hline BC9 & $\mathrm{C}$ & 110 & 2.65 & 16 & 6 & $\mathbf{1 9 7} \pm 15$ & $\mathbf{3 . 3} \pm 0.8$ & $\mathbf{1 7 . 1} \pm 6$ & $290 \pm 25$ \\
\hline \multicolumn{10}{|c|}{$\sim 7-8 \% \mathrm{YSZ}$} \\
\hline $\mathrm{TC} 1$ & $\mathrm{E}$ & 80 & 1.1 & 6 & 6 & $143 \pm 21$ & $12.0 \pm 4$ & - & $\mathbf{4 1 0} \pm 29$ \\
\hline $\mathrm{TC} 2$ & $\mathrm{E}$ & 80 & 1.1 & 12 & 3 & $185 \pm 18$ & $\mathbf{1 7 . 0} \pm 4$ & - & $\mathbf{3 0 7} \pm 53$ \\
\hline TC3 & $\mathrm{E}$ & 80 & 1.1 & 12 & 6 & $\mathbf{7 5} \pm 14$ & $13.4 \pm 5$ & - & $\mathbf{3 7 8} \pm 43$ \\
\hline $\mathrm{TC} 4$ & $\mathrm{E}$ & 80 & 1.1 & 8 & 3 & $\mathbf{2 2 0} \pm 13$ & $10.6 \pm 3$ & - & $\mathbf{5 0 8} \pm 48$ \\
\hline TC5 & $\mathrm{E}$ & 80 & 1.1 & 5 & 5 & $104 \pm 18$ & $14.2 \pm 3$ & - & $416 \pm 32$ \\
\hline TC6 & $\mathrm{E}$ & 100 & 1.1 & 5 & 5 & $\mathbf{8 6} \pm 12$ & $14.8 \pm 2$ & - & $392 \pm 23$ \\
\hline TC7 & $\mathrm{E}$ & 120 & 1.1 & 5 & 5 & $62 \pm 13$ & $15.1 \pm 5$ & - & $\mathrm{N} / \mathrm{A}$ \\
\hline TC8 & $\mathrm{F}$ & 80 & 1.1 & 5 & 5 & $\mathbf{1 3 2} \pm 12$ & $16.9 \pm 3$ & - & $382 \pm 34$ \\
\hline TC9 & $\mathrm{F}$ & 100 & 1.1 & 5 & 5 & $\mathbf{9 4} \pm 16$ & $18.5 \pm 3$ & - & $\mathbf{3 6 5} \pm 46$ \\
\hline TC10 & $\mathrm{F}$ & 120 & 1.1 & 5 & 5 & $72 \pm 10$ & $19.3 \pm 5$ & - & $\mathrm{N} / \mathrm{A}$ \\
\hline TC11 & G & 60 & 1.1 & 12 & 5 & $\mathbf{8 7} \pm 15$ & $\mathbf{2 2 . 3} \pm 4$ & - & $\mathbf{3 0 3} \pm 42$ \\
\hline TC12 & G & 80 & 1.1 & 12 & 5 & $\mathbf{5 3} \pm 13$ & $\mathbf{2 3 . 1} \pm 2$ & - & $\mathbf{2 9 1} \pm 34$ \\
\hline TC13 & G & 100 & 1.1 & 12 & 5 & $\mathbf{2 3} \pm 8$ & $\mathrm{~N} / \mathrm{A}$ & - & $\mathrm{N} / \mathrm{A}$ \\
\hline TC14 & $\mathrm{H}$ & 60 & 1.1 & 12 & 5 & $\mathbf{1 7 4} \pm 23$ & $20.9 \pm 5$ & - & $\mathbf{2 9 4} \pm 46$ \\
\hline TC15 & $\mathrm{H}$ & 80 & 1.1 & 12 & 5 & $\mathbf{1 2 0} \pm 17$ & $\mathbf{2 1 . 4} \pm 4$ & - & $\mathbf{2 6 7} \pm 54$ \\
\hline TC16 & $\mathrm{H}$ & 100 & 1.1 & 12 & 5 & $\mathbf{8 8} \pm 14$ & $\mathbf{2 2 . 6} \pm 2$ & - & $\mathrm{N} / \mathrm{A}$ \\
\hline
\end{tabular}

sample holder. A summary of the CFS deposition parameters is reported in Tab. 5 .

The deposited coatings were prepared for optical and SEM metallographic analysis by mechanical cutting, the obtained sections being vacuum mounted into low viscosity epoxy resin and then mechanically polished to a surface roughness $\mathrm{Ra} \sim 0.04 \mu \mathrm{m}$. Optical micrographs were taken at X200 magnification and a quantitative analysis of porosity and oxide strings was carried out (using the software Image ${ }^{\circledR}$ ) based on ASTM E2109-01. The values of the mentioned quantities have been reported as an average over 20 fields of view and the corresponding error value was determined as mean standard deviation. Micro-hardness was obtained by using a 1600-6400 hardness tester machine with a Knoop indenter at 300 gf load; 10 measurements have been carried out with mean and standard deviation values calculated. SEM micrographs were obtained by first coating the cross-sections with a thin layer of conductive platinum. The crystal structure was characterized on the as-deposited coatings with a Siemens ${ }^{\circledR}$ D500 diffractometer using $\mathrm{CuK}$ radiation. Scans with a step size of $0.01^{\circ}$ and step time of $2 \mathrm{~s}$ were conducted with $2 \theta$ values ranging from $35^{\circ}$ to $85^{\circ}$ and $20^{\circ}$ to $80^{\circ}$ for CoNiCrAlY and $\sim 7-$ $8 \%$ YSZ respectively.

Ni-based superalloy Nimonic C263 was used as substrate to produce thermal fatigue specimens, with surface preparation routines kept as previously specified. In order to remove the influence of the bondcoat from the results, the bondcoat layer for the CFS samples was also sprayed via APS. Bondcoat/topcoat thickness of 150/300 $\mu \mathrm{m}$ were targeted in all specimens. Samples were heated up in air to $1135^{\circ} \mathrm{C}$, held at this temperature for $3 \mathrm{hr}$, and then cooled down at ambient temperature for $0.3 \mathrm{hr}$. The thermal cycle lifetime was defined as the time elapsed between the beginning of the test to when $50 \%$ of the top coat area had delaminated. Mean and standard deviation were determined, for each technique, with 6 deposited specimens. 


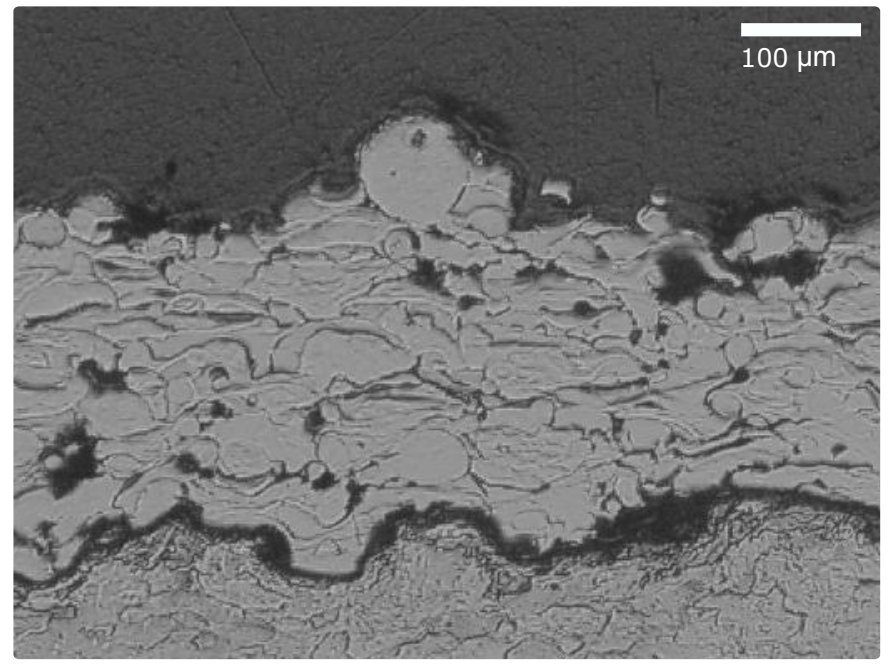

(a) BC2 (powder size: $-90+45 \mu m$ )

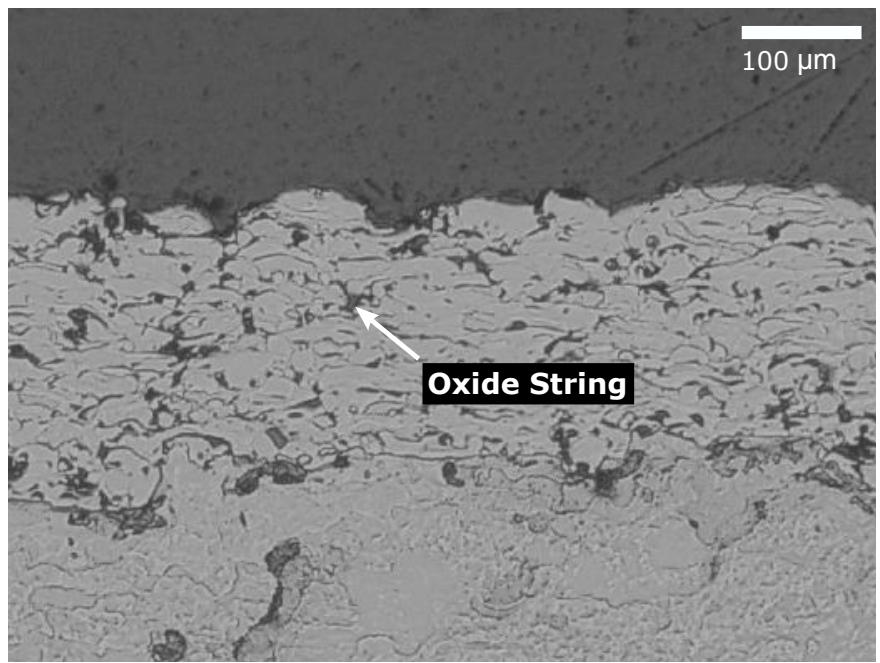

(b) BC5 (powder size: $-45+22 \mu m$ )

Figure 2: Cross-sectional optical micrographs of CoNiCrAlY specimens BC2 and BC5 showing how a lower starting powder nominal size corresponds to lower thickness and unmolten particles presence, together with an increased oxidation level.

\section{Results \& Discussions}

Microstructure results for the CFS-deposited coatings, together with the process parameters used are reported in Tab. 5. In the following paragraphs, the main aspects regarding the influence of each of the deposition parameters on the experimental results will be evaluated.

\subsection{Powder type (Size/Shape)}

In CoNiCrAlY materials, a reduction in powder size was observed to lead to a decrease in coating thickness and porosity and an increase in oxide string content. A lower coating porosity (with consequent increased microhardness) was obtained with HOSP-produced powders in $\sim 7-8 \%$ YSZ experiments.

As an example, the reduction in used powder size from sample BC2 (A: $-90+45 \mu m$ ) to BC5 (B: $-45+22 \mu m$ ) corresponds to a decrease in thickness (238 to $195 \mu \mathrm{m})$, porosity (4 to 1.9 area\%) and an increase in oxide strings (11.3 to 22.4 area\%) respectively (Fig. 2).

In this respect, a change in powder size (i.e. average diameter) mainly affects the particle melting heat $\left(Q_{M}\right)$. Thus, the heat required to melt a CoNiCrAlY particle of diameter $d_{p}$ can be estimated from Eq. 3 and the material properties in Tab. 3 as $Q_{M}=d_{p}^{3} \cdot 3.15 \cdot 10^{10} \mathrm{~J}$. By then substituting the mean diameters of powders $\mathrm{A}$ and B, we obtain: $Q_{M}(\operatorname{powder} A)=2.3 \cdot 10^{-2} J$ and $Q_{M}($ powder $B)=2.9 \cdot 10^{-3} \mathrm{~J}$, which predicts an easier in-flight melting for the latter powder compared to the former. Although an accurate computation of dwell time (as per Eq. 2 would be required for the two powders to calculate the actual molten fraction, the above quantities show, in simple terms, the marked effect of powder size on melting characteristics. Moreover, since less heat is required to melt particles of smaller dimension, this corresponds to higher particle temperature $T_{p}$ and hence from Eq. 5 a faster oxidation rate is also expected, as confirmed by the experimental results. The effect of powder shape variation can be shown by comparing $\sim 7-8 \%$ YSZ specimens TC5 and TC15, sprayed at the same conditions except powder feed rate $(5 \mathrm{~g} / \mathrm{min}$ and $12 \mathrm{~g} / \mathrm{min}$ respectively) and starting powder (E, HOSP and H, Plasma Spheroidized respectively). Neglecting the effect of the powder feed rate on the measured coating thickness, the main effect of powder change from TC5 to TC15 is an increase in porosity (14.2 to 21.4 area\%) and a corresponding reduction in microhardness (416 to $267 \mathrm{HK}_{0.3}$ ). The hollow structure of HOSP-produced powders, compared to denser plasma spheroidized ones, provides them with a higher porosity. The effect of this increased powder porosity on in-flight particle properties is quite complex as it involves reduction in powder thermal conductivity, gas entrapment kinetics and diameter reduction during flight [17, 18. Assuming for instance that an increase in porosity from powder $\mathrm{H}$ to E corresponds to a decrease in overall in-flight particle density $\rho_{p}$ and diameter $d_{p}$, Eq. 3 predicts a reduction in melting heat. This, together with an increase in particle velocity due to diameter reduction, improves the splat deformation and thus accounts for the lower porosity and higher hardness observed from spraying HOSP powders (TC5) compared to Plasma Spheroidized ones (TC15). This proven superior performance of HOSP-produced powders in respect to other types of traditional materials (e.g. agglomerated, crushed) confirms similar findings on APS depositions of the same materials 19]

Finally, it is worth mentioning that by separate tests on CFS deposition by using HOSP-produced Metco 204B-NS (D, Tab. 11, also employed in this study to spray the APS topcoat layer and of considerable higher nominal size distribution than powders E-F-G-H, no material sticking 


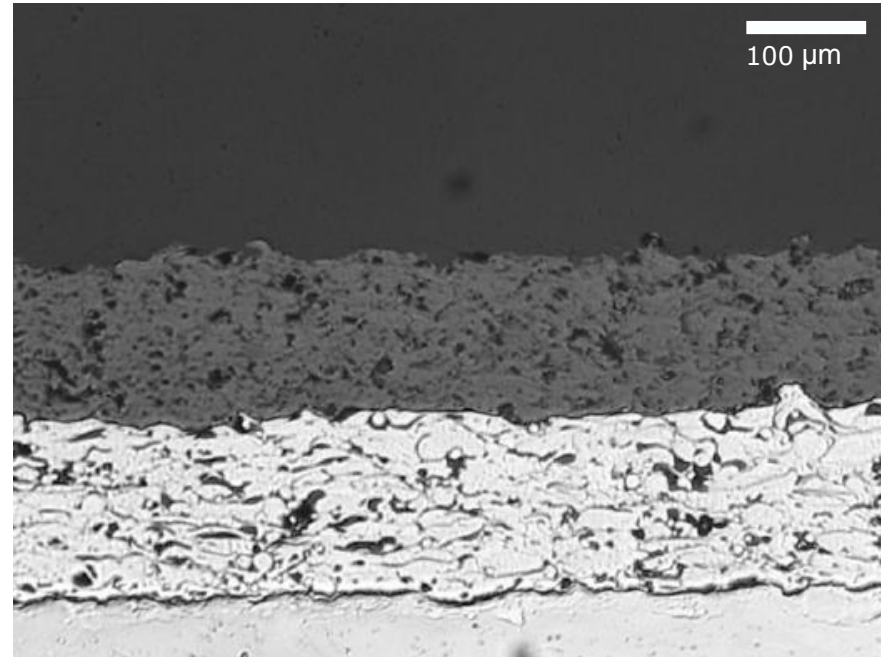

(a) TC8 (standoff distance: $80 \mathrm{~mm}$, porosity: 16.9\%)

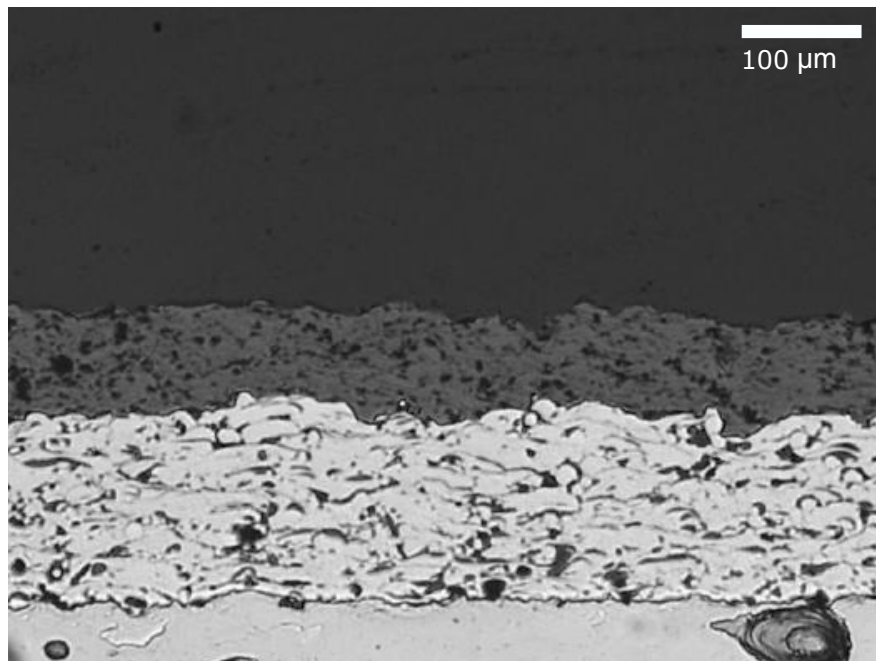

(b) TC9 (standoff distance: $100 \mathrm{~mm}$, porosity: 18.5\%)

Figure 3: Cross-sectional optical micrographs of $\sim 7-8 \%$ YSZ specimens (a) TC8 and (b) TC9, showing how an increased standoff distance leads to increased porosity at the deposition conditions employed.

was observed, again likely due to size-dominant effects as described by Eq. 3 .

\subsection{Standoff distance}

The main effect of standoff distance increase in both CoNicrAlY and $\sim 7-8 \%$ YSZ materials is a reduction in coating thickness, increase of porosity and consequent decrease in microhardness. In fact, in all the specimens deposited during this study, the thickest and less porous layers are observed at the lowest standoff distances selected for each powder used.

As an example of the abovementioned effect, specimen TC8 and TC9 (Fig. 3), sprayed from powder F at the same deposition conditions except standoff distance $(80$ and $100 \mathrm{~mm}$ respectively), reveals a measured thickness of 132 and $94 \mathrm{~mm}$, porosity of 16.9 and 18.5 area\% and $H K_{0.3}$ microhardness of 382 and 365 respectively. This would suggest a lower melting for the particles deposited at higher SOD. At a first analysis, an increase in particle dwell time $\tau$ is expected with an increase in standoff distance, with the consequence that a higher in-flight heat transfer would be also obtained (Eq. 11). The opposite observed result, however, could be explained by the flame temperature decrease with standoff distance, as proven by Bandyopadhyay [20] through CFD simulations in comparable SOD to the ones tested in this work. In their study, although using a different nozzle geometry and gases deposition parameters, a steep decrease in flame temperature from the adiabatic $3400 \mathrm{~K}$ at $10 \mathrm{~mm}$ from the nozzle exit to $\sim 1000 \mathrm{~K}$ at $50 \mathrm{~mm}$ is determined. A flame temperature $\left(T_{\infty}\right.$, Eq. 2$)$ lower than the particle temperature at a given time in flight would correspond to a convective cooling term. An accurate analysis of the particle transient molten fraction, out of scope for the current work, is rather complex as it requires knowledge of the in flight thermal history and molten state.

\subsection{Equivalence ratio}

In CoNiCrAlY materials, an increase of gas equivalence ratio from a neutral to a fuel-rich one was proven to minimise the level of oxide strings.

The effect can be appreciated by comparing specimens BC0 (Fig. 5) and BC5 (Fig. 2(b)), sprayed at the same conditions except acetylene-to-oxygen equivalence ratio ( $\Phi=1$ and $\Phi=2.65$ respectively) which reveals a decrease in oxide strings from 38.6 to 11.3 area\%; the reduction in flame temperature and oxygen partial pressure can be considered as causes for this behaviour. Following the work of Hewitt 9 on oxyfuel gas processes, estimated flame temperatures $T_{\infty}$ of $\sim 3200$ (at $\Phi=1$ ) and $\sim 3100$ (at $\Phi=2.65$ ) can be predicted. As described by Eqs. 1 and2, a lower flame temperature corresponds in lower heat transferred to the in-flight particle, with the consequence that a lower particle temperature $T_{p}$ will be experienced and in turn also slowing down the oxidation kinetics (Eq. 5). Moreover, the reduction in oxygen content experienced from the use of a reducing equivalence ratio (as in the case of $\Phi=2.65$ ), greatly reduces its partial pressure around the particle surface which results in the decrease of collision frequency between oxygen and metal molecules on the particle, as is taken into account by the pre-exponential term $A$ in Eq. 5 .

\subsection{Powder feed rate}

A marked decrease in coating thickness, increase in porosity and consequently lower microhardness, has been observed in $\sim 7-8 \%$ YSZ coatings following a consistent raise in powder feed rate. 


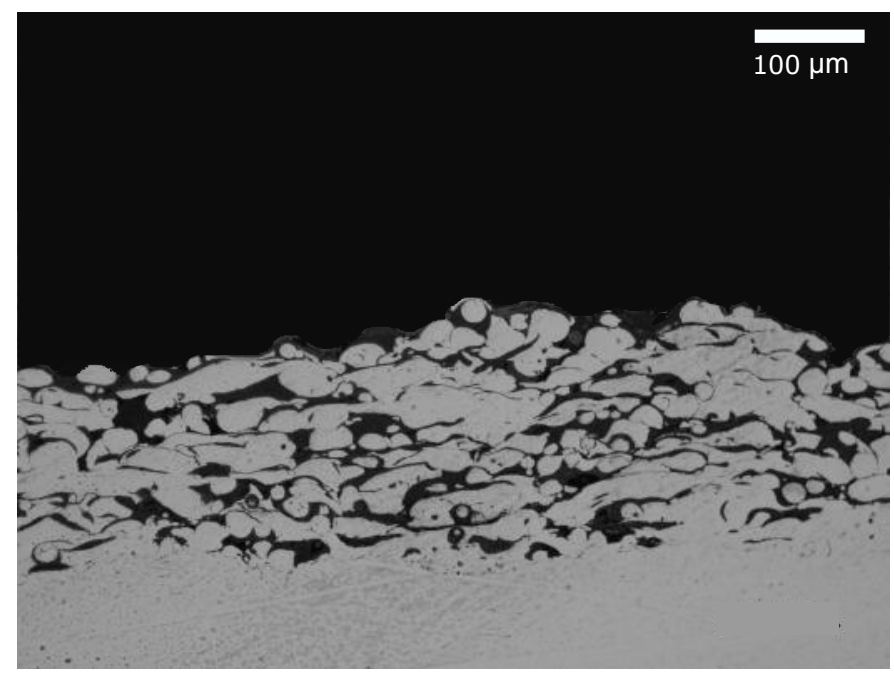

Figure 5: Cross-sectional optical micrograph of specimen B0, deposited at a $\Phi=1$ equivalence ratio. Note the higher oxidation level compared to sample BC5 (Fig. 2(b)), sprayed at $\Phi=2.65$.

The effect can be observed by comparing specimens TC1 and TC3 (Fig. 4) which were sprayed at the same deposition conditions except powder feed rate $(6$ and 12 $\mathrm{g} / \mathrm{min}$ respectively) and where a thickness of 143 and 75 $\mu \mathrm{m}$, porosity of 12 and 13.4 area $\%$ and microhardness of 410 and $378 H K_{0.3}$ were reported respectively. This property, also referred to as loading effect, can be ascribed to a reduction in flame temperature and flow caused by an excessive flame-to-particle heat and momentum transfer. The magnitude of this transfer is fixed and determined by the combustion gases flows and pressure. Thus, it is clear that an overloading of the flame with powder material would not allow all the particles to uniformly melt, leading to the abovementioned effect. It is thus useful to quantify the magnitude of this effect in terms of the powder-to-jet mass flow ratio $\left(M_{F}\right.$, Eq. 4 ). By assuming the experimental gases pressures and flow values used to deposit specimens TC1 and TC3, it can be demonstrated that: $M_{F}(\mathrm{TC} 1)=20 \%$ and $M_{F}$ (TC3) $=41 \%$, and thus the loading effect plays a considerable role in both cases. The reduction in flame temperature and flow induced by loading produces in turn a decrease transferred heat $\left(Q_{\text {int }}\right.$, Eq. 2 and particle velocity $\left(v_{p}\right)$, negatively affecting the splat melting, spreading behaviour and thus coatings microstructure properties.

A similar conclusion, is observed by comparing the results of specimens TC2 and TC4, sprayed at the same parameters except powder feed rate: 12 and $8 \mathrm{~g} / \mathrm{min}$ respectively. This reduction in powder feed rate leads to considerable improvement in all the microstructure properties assessed: thickness increases from 185 to $220 \mu \mathrm{m}$, porosity reduces from 17 to 10.6 area $\%$ and microhardness increases from 307 to $508 \mathrm{HK}_{0.3}$. It is worth pointing out that in practical applications the powder feed rate is always set at the highest level to give maximum deposition throughput, hence loading effect (including powder feed rate and carrier gas effects) generally plays a relevant role also in CFS process optimisation.

\subsection{Carrier Gas flow}

In $\sim 7-8 \%$ YSZ coatings, a substantial increase in coating thickness and porosity, together with a related decrease in microhardness is observed when the carrier gas flow is decreased while keeping a high powder feed rate.

The effect can be observed by comparing the results for specimens TC3 and TC2, sprayed at the same deposition conditions except carrier gas flow rate (6 and $3 \mathrm{slpm}$ respectively) resulting in a increase of thickness from 75 to

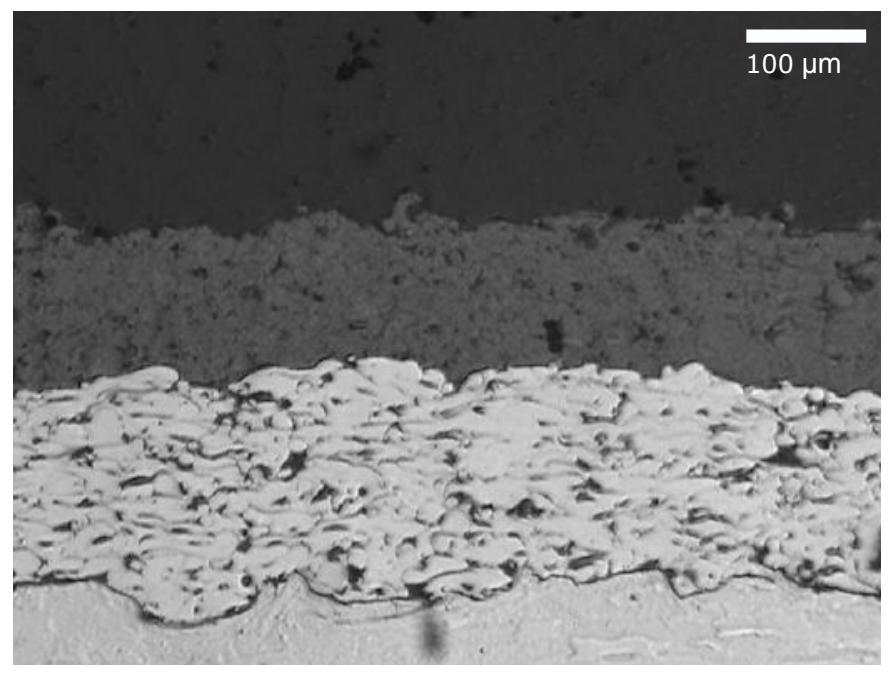

(a) TC1 (powder feed rate: $6 \mathrm{~g} / \mathrm{min}$, porosity: $12 \%$, microhardness: $\left.410 H K_{0.3}\right)$

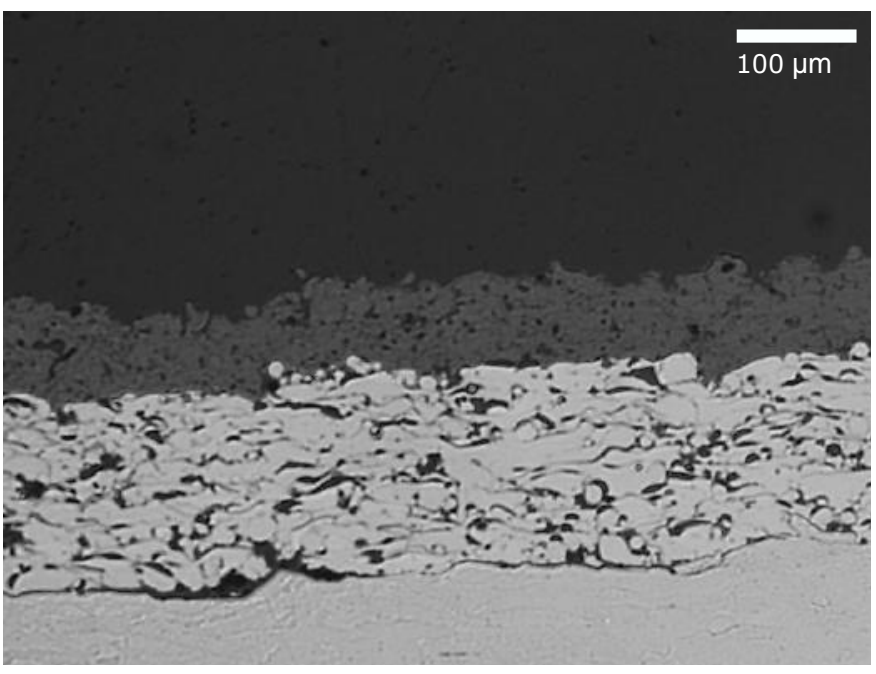

(b) TC3 (powder feed rate: $12 \mathrm{~g} / \mathrm{min}$, porosity: $13.4 \%$, microhardness: $\left.378 H K_{0.3}\right)$

Figure 4: Cross-sectional optical micrographs of $\sim 7-8 \%$ YSZ specimens (a) TC1 and (b) TC3 showing how an excessive powder feed rate increases coating porosity due to "loading" effect. 
Table 6: Final comparison of microstructure results obtained from the bondcoat-topcoat APS coatings APS_BC-APS_TC versus CFS BC5TC4.

\begin{tabular}{|c|c|c|c|c|}
\hline & \multicolumn{2}{|c|}{ Bondcoat } & \multicolumn{2}{|c|}{ Topcoat } \\
\hline & APS_BC & BC5 & APS_TC & TC4 \\
\hline Material & $\mathrm{CoNiCrAlY}$ & $\mathrm{CoNiCrAlY}$ & $\sim 7-8 \% \mathrm{YSZ}$ & $\sim 7-8 \% \mathrm{YSZ}$ \\
\hline Powder \# & A & $\mathrm{B}$ & $\mathrm{D}$ & $\mathrm{E}$ \\
\hline Porosity [area \%] & 1.8 & 1.9 & 9.5 & 10.6 \\
\hline Oxide Strings [area \%] & 14.5 & 22.4 & - & - \\
\hline $\mathbf{H K}_{0.3}[-]$ & 290 & 283 & 602 & 508 \\
\hline
\end{tabular}

$185 \mu \mathrm{m}$, higher porosity (from 12 to 17 area \%) and lower microhardness (from 410 to $307 H K_{0.3}$ ). The neutral gas used as carrier, argon, does not take part in the combustion reaction, but instead absorbs heat and flow, reducing temperature and mass flux from the flame. Hence, although a minimum amount of carrier gas flow is required to impart an initial acceleration to the particles stream, its value has to be optimised in order to avoid an excessive cool- and slow-down effect of the in-flight particles (loading effect). By quantifying the powder-to-jet mass flow ratio (Eq. 4), for the two specimens under analysis, gives: $M_{F}(\mathrm{TC} 3)=$ $41 \%$ and $M_{F}(\mathrm{TC} 2)=44 \%$. It is clear that a decrease in carrier gas flow from sample TC3 to TC2, brings to an increase rather that a lowering in loading effect, as it is the overall mass flow ratio between the powder and all the combustion gases and not the single carrier gas flow value to appear in the $M_{\text {jet stream }}$ term in Eq. 4. This higher loading effect, together with a decrease in particles initial speed, causes a decrease in particles thermal and kinetic energy, thus worsening their spreading behaviour and leading to a thicker and porous coating.

Following these results, specimen TC4 was sprayed at the same conditions of sample TC2, except for a lower value of powder feed rate ( 8 instead of $12 \mathrm{~g} / \mathrm{min}$ ). The decrease in loading effect, confirmed by a lower value of the mass flow ratio $M_{F}(\mathrm{TC} 4)=29 \%$, corresponds to increased coating thickness, lower porosity and higher microhardness than any of the other specimens produced.

\subsection{Comparison to APS coatings}

To further characterise microstructure features observed in CFS-deposited coatings, a comparison to APS specimens produced at aerospace standard conditions has been performed; specimens BC5 and TC4, due to their closer match in metallographic properties to the APS-produced layers were thus compared. Results are summarised in Tab. 6.

The results show that lower values in all attributes are obtained in APS specimens. Specifically, both APS_BC and B5 coatings match considerably well in porosity and microhardness, and a remarkable difference in oxide string content is also observed: $-67 \%$ for the APS specimen. APS_TC and TC4 show instead a closer match in both porosity and microhardness, with percentage differences reading -6 and $+15 \%$ respectively for the former specimen. These higher values of oxide strings and porosity (with related decrease in macrohardness) observed in CFS- compared to APS-deposited specimens can be explained by recalling Eqs. 1,5 for the two technologies. Table 7 summarizes the main differences in features between the two deposition methods for the case of CoNiCrAlY powders $\mathrm{A}$ (APS) and $\mathrm{B}$ (CFS). In the table,

Table 7: Comparison between standard deposition parameters and relevant calculated jet-to-particle interaction properties for CFS and APS deposition. Values for CoNiCrAlY powder A (APS) and B (CFS) are chosen for parameters particle speeds and diameter.

\begin{tabular}{|c|c|c|}
\hline Property & CFS & APS \\
\hline Jet Gas Type & $\mathrm{O}_{2} / \mathrm{C}_{2} \mathrm{H}_{2}$ & $\mathrm{Ar} / \mathrm{H}_{2}$ \\
\hline $\begin{array}{l}\mathbf{T}_{\infty} \text { Jet Temperature } \\
(\mathrm{K}) 13\end{array}$ & $2500-4000$ & $>10000$ \\
\hline $\begin{array}{l}\mathbf{v}_{\mathbf{p}} \text { Particle Speed } \\
(\mathrm{m} / \mathrm{s})^{a}\end{array}$ & 50 & 150 \\
\hline $\begin{array}{l}M_{\text {jet stream }} \text { Gases Mass Flow } \\
(\mathrm{g} / \mathrm{s}) 2\end{array}$ & 0.5 & 1.5 \\
\hline $\begin{array}{l}\text { h Heat Transfer Coefficient } \\
\cdot 10^{4}\left(\frac{W}{m^{2} K}\right) \frac{21}{}\end{array}$ & 0.7 & 1.4 \\
\hline $\begin{array}{l}\mathbf{d}_{\mathbf{p}} \text { Particle Diameter } \\
(\mu \mathrm{m})\end{array}$ & 45 & 90 \\
\hline $\begin{array}{l}\tau \text { Dwell Time } \\
\cdot 10^{-3}(\mathrm{~s})^{b}\end{array}$ & 2 & 0.9 \\
\hline $\begin{array}{l}\text { QM }_{\mathrm{M}} \text { Melting heat } \\
\cdot 10^{-6}(\mathrm{~J})^{c}\end{array}$ & 0.5 & 3.2 \\
\hline $\begin{array}{l}\text { Qint Heat Transferred } \\
(\mathrm{W})^{d}\end{array}$ & 0.2 & 4.0 \\
\hline \multicolumn{3}{|c|}{$\begin{array}{l}a \text { as measured with Tecnar }{ }^{\mathbb{B}} \text { Accuraspray G3C, } \\
b \text { assuming } 0.10 \text { (CFS) }-0.15 \mathrm{~m} \text { (APS) standoff distances, } \\
\text { c } \\
\text { from Eq. } 3 \\
\text { from Eq. } 2\end{array}$} \\
\hline
\end{tabular}

known maximum jet temperatures $T_{\infty}$, average particle speeds $v_{p}$ and gases mass flow $M_{\text {jet stream }}$ are reported for the two technologies. The heat transfer coefficient $h$ for APS has been extrapolated from the work of Xiong ([21]) and the value for CFS was assumed to be approximately one third of the same quantity. The calculations on dwell time $\tau$, melting heat $Q_{M}$ and heat transferred $Q_{\text {int }}$ were then calculated based on an average particle powder size $d_{p}$ from the ones used in the current study: B, E (CFS) and A, D (APS) by taking average thermal and physical properties for CoNiCrAlY and $\sim 7-8 \%$ YSZ materials from Tab. 3. A higher partial pressure of oxygen and a longer dwell time can be considered to explain the higher oxide strings content $(+67 \%)$ observed in specimen 


\section{CFS}
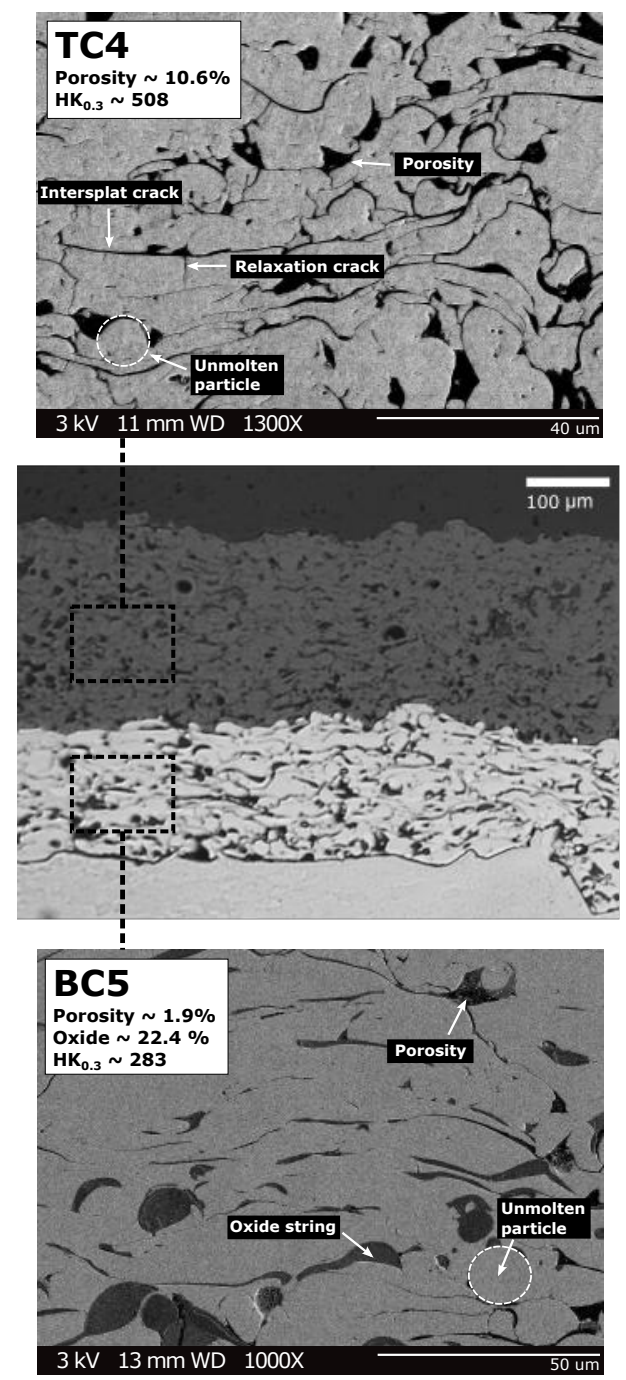

APS
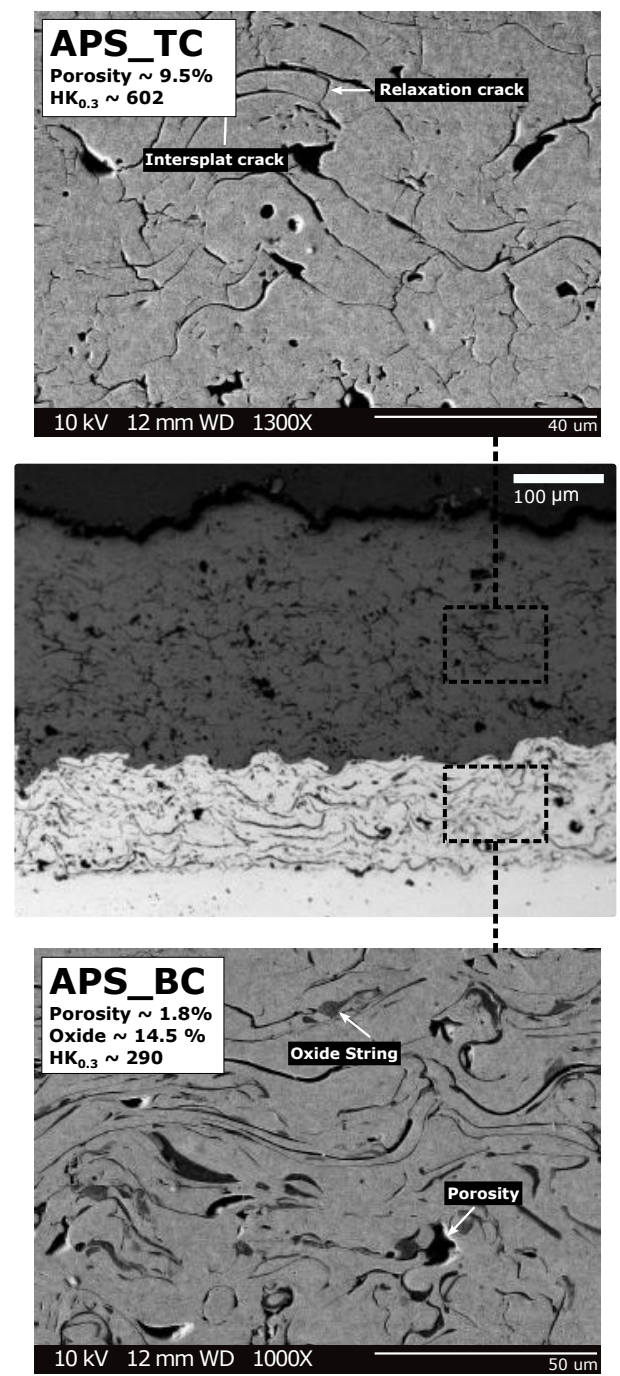

Figure 6: Cross-sectional optical and SEM micrographs of CFS (left) and APS (right) coatings compared, visually confirming differences in the measured microstructural features (Tab. 6)

BC5 compared to APS_BC. In CFS, the pre-exponential collision term $A$ in Eq. 5 will be high because oxygen is used as combustible gas as compared to the APS $\mathrm{Ar} / \mathrm{H}_{2}$ oxygen-free stream where oxygen is only present due to natural entrapment in the turbulent jet. Moreover, particle dwell time experienced in CFS deposition results considerably higher than APS thus increasing its exposure time to the oxidising atmosphere in the former case. It is interesting to note that a higher in-flight particle temperature is expected in APS deposition compared to CFS due to higher flame temperature. However the larger value of melting heat $\left(Q_{M}\right.$, Eq. 3) caused by the use of powders of increased average diameter in the former case probably balances this effect, generating powders with similar temperature with the two deposition technologies. Thus, f similar particle temperatures are assumed, the lower porosity observed in APS_TC compared to TC4 can be considered a consequence of the higher particle kinetic energy experienced in APS deposition compared to CFS (due to differences in particle speeds $v_{p}$, Tab. 7).

These microstructural differences are also highlighted by a close look to SEM micrographs of the same coatings (Fig. 6). It is immediately apparent that a general lower melting is observed in CFS-deposited BC5 layer compared to APS_BC due to the abovementioned lower kinetic energy possessed by in-flight particles. This generates a higher amount of unmolten particles, in the former layer, also accounting for the concentration of oxide strings of wider area compared to the more fragmented localisation observed in APS_BC. A look at the single splats composing these coatings confirms this lower flattening and higher oxide layer extension observed in CFS-deposited CoNiCrAlY materials (Figs. 7(c) and (d). With regards $\sim 7-8 \%$ YSZ materials, the higher porosity measured in 


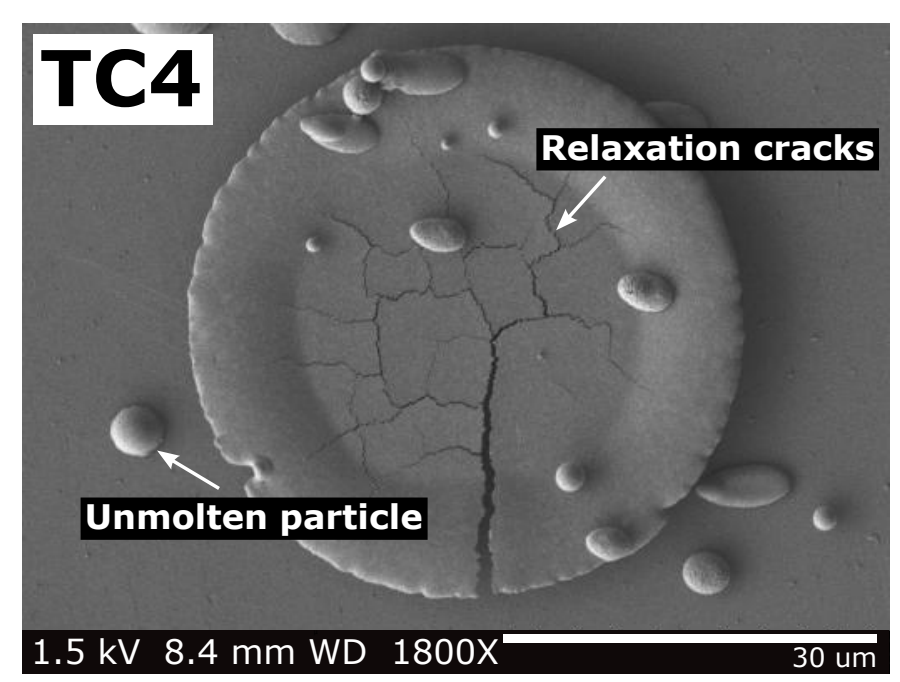

(a)

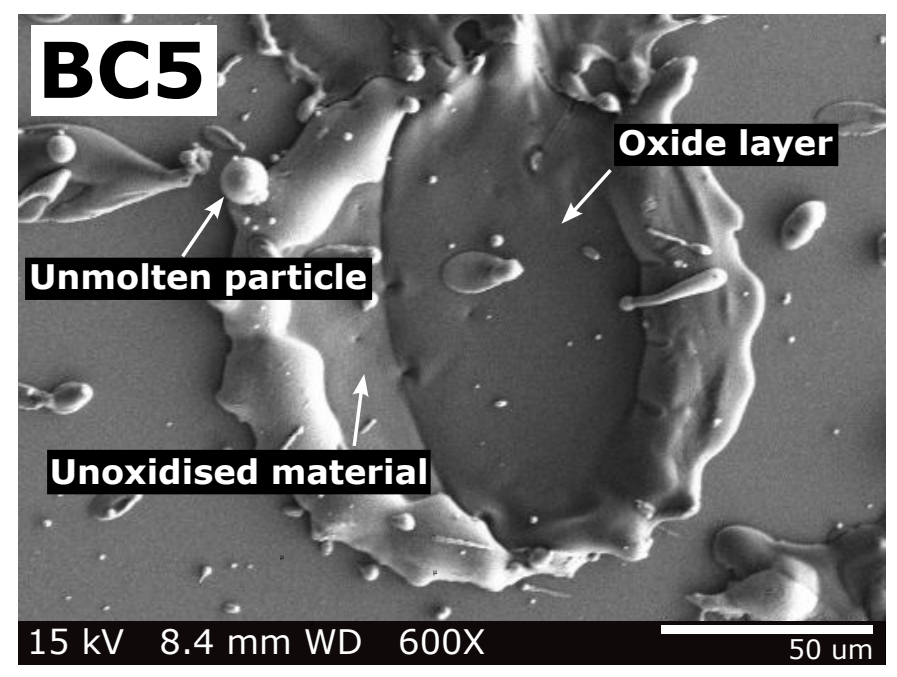

(c)

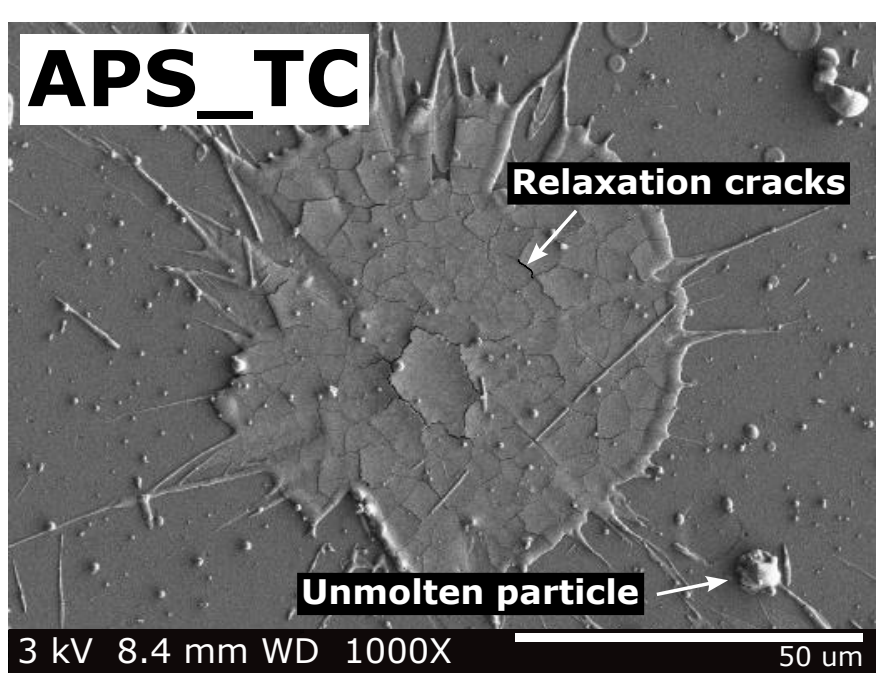

(b)

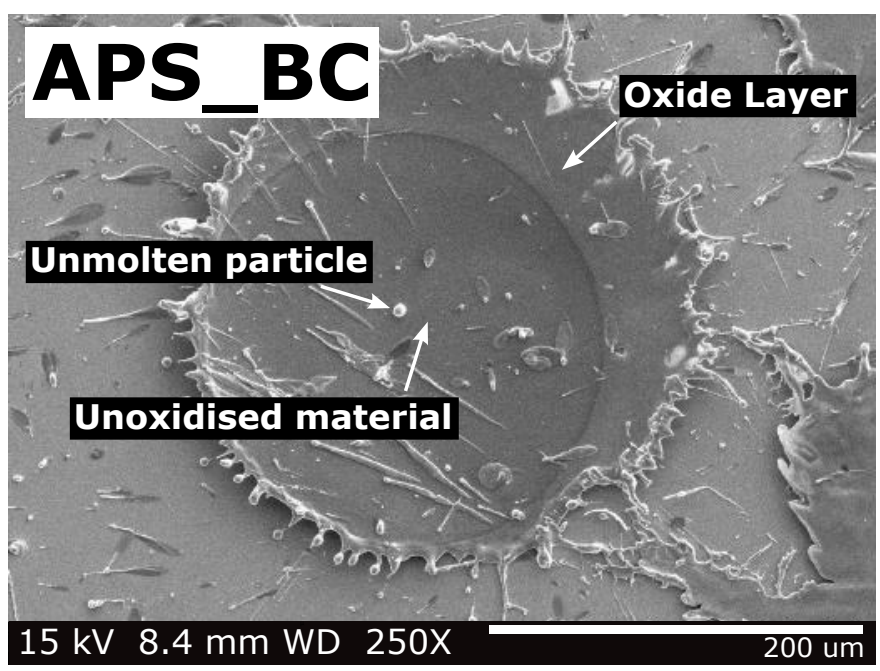

(d)

Figure 7: Top-view SEM micrographs of single splats composing the CFS and APS coatings compared, showing relevant microstructural features.

CFS-deposited TC4 compared to APS_TC is clearly observed in Fig. 6. The less flattening experienced by the particles in the former case corresponds again to a higher presence of unmolten material, which constitutes uneven areas for the successive impact of incoming particles, generating porosity. The same micrographs also show the presence of intersplat and relaxation cracks, both generated by residual stresses relaxation mechanisms during deposition [22]. The presence of relaxation cracks in both materials and the lower flattening observed in TC4 as compared to APS_TC can be appreciated at a single splat level in Fig. 7(a) and (b).

In order to further characterise and understand possible phase transformations induced by the two deposition techniques, XRD analysis was performed both on the starting powders and on the produced coatings (Fig.
8. It is worth noting that both CoNiCrAlY powders $\mathrm{A}$ and $\mathrm{B}$ contain a certain amount of $\beta$ phase dispersed in a $\gamma$ matrix (Fig. 8a) while in both corresponding coatings BC5 and APS_BC the same is absent (Fig. 8(c)). The absence of a $\beta$ phase in CoNiCrAlY APS-deposited coatings has been reported in literature [23, while the observation of the same in CFS-deposited layers is instead novel in this work. This is an interesting and not expected result since $\beta-N i A l$ is generally found in as-sprayed coatings deposited through combustion techniques as High Velocity Oxyfuel Spray (HVOF) [23, 4]. The effect is here ascribed to solidification kinetics, since the considerable (and higher than expected in HVOF) cooling rate experienced by the in-flight droplets at impact with the substrate would affect the level of $\beta$-precipitation. A compliance in phases is also observed in the $\sim 7-8 \% \mathrm{YSZ}$ powders $\mathrm{E}$ and $\mathrm{D}$, showing monoclinic traces in a matrix 


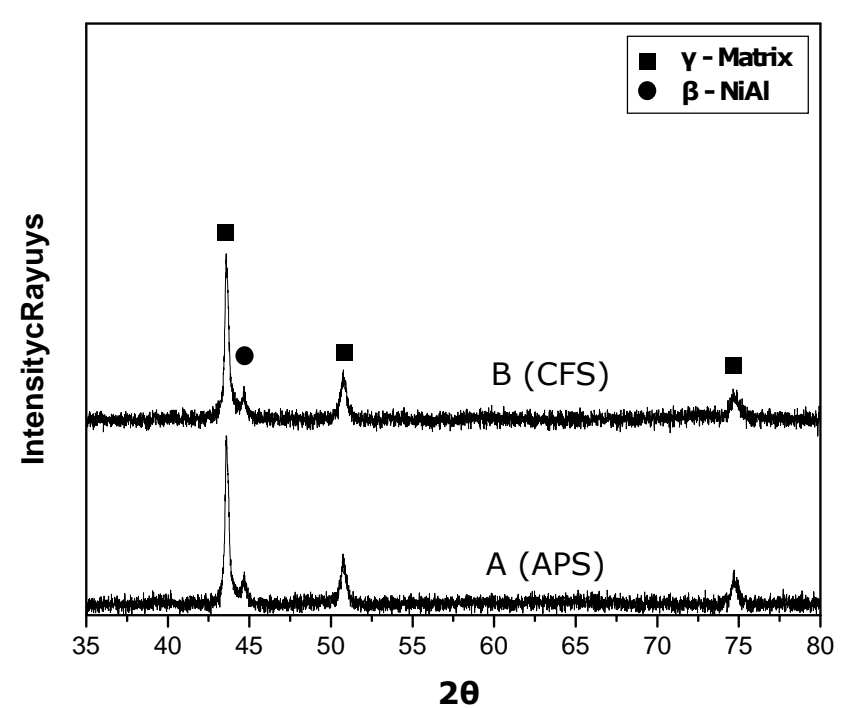

(a) CoNiCrAlY Powders: B(CFS) and A(APS)

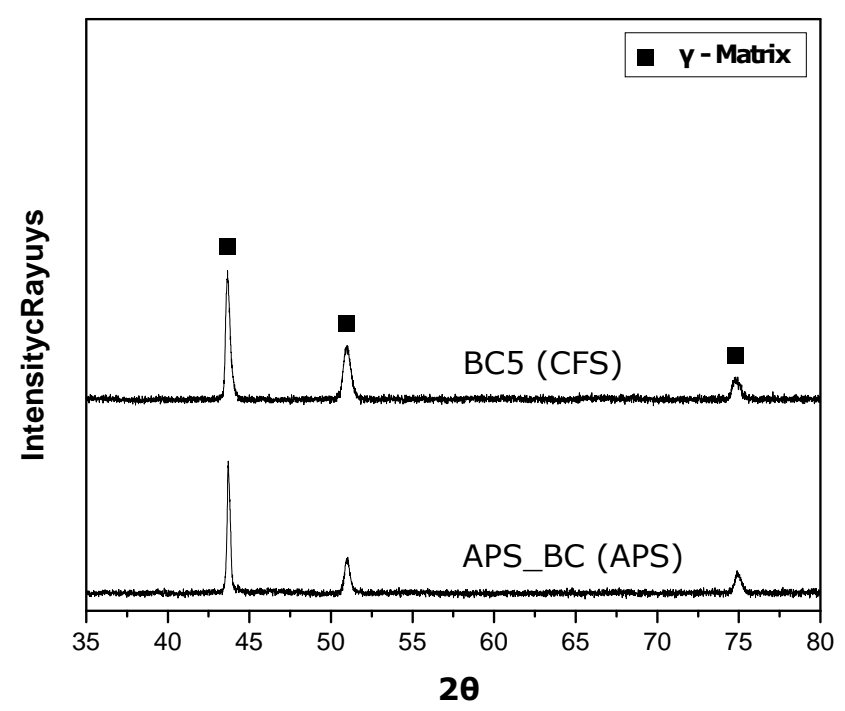

(c) CoNiCrAlY Coatings: BC5(CFS) and APS_BC(APS)

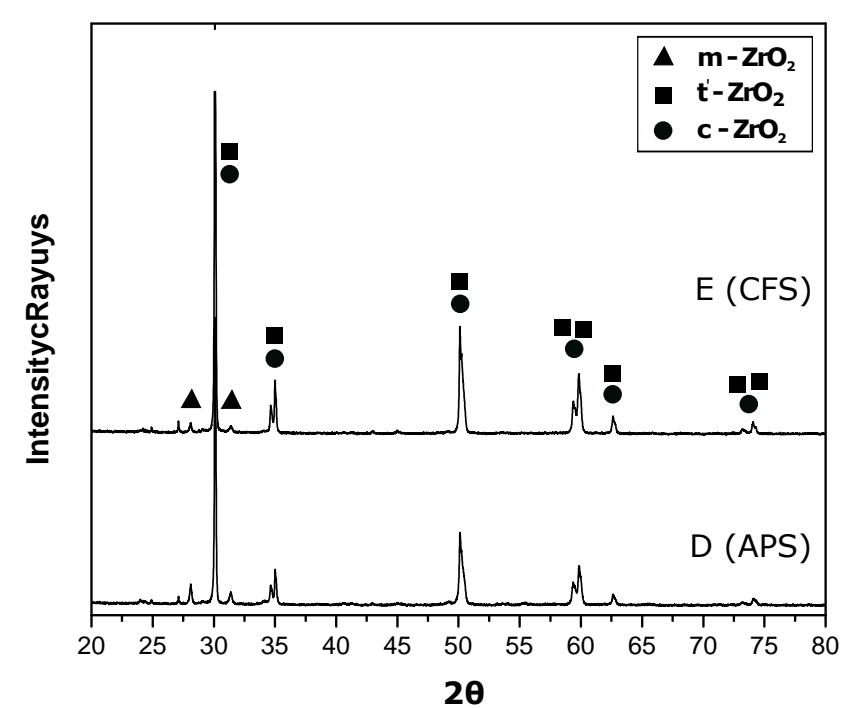

(b) 7-8\% YSZ Powders: E(CFS) and D(APS)

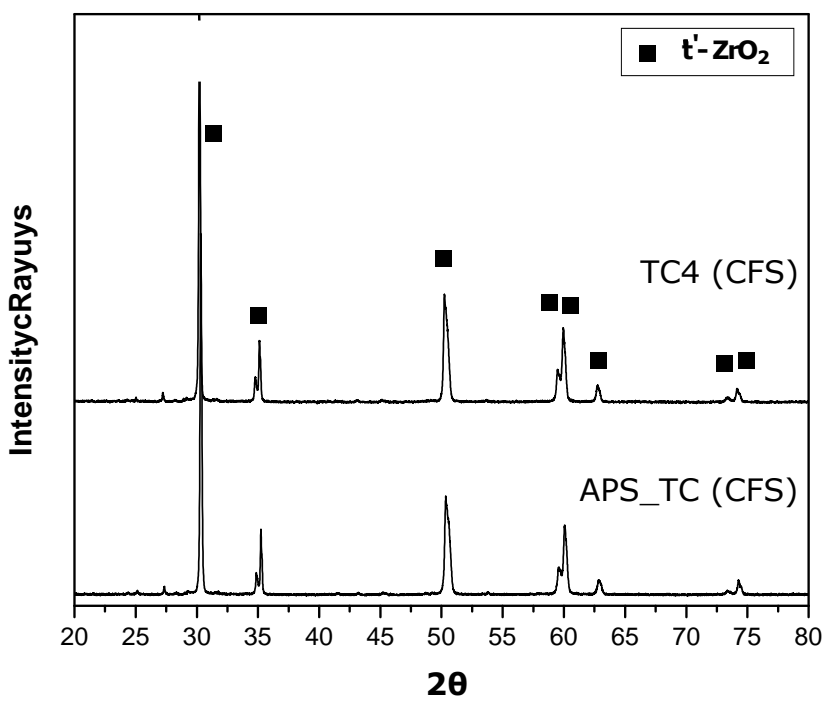

(d) $\sim 7-8 \%$ YSZ Coatings: TC4(CFS) and APS_TC(APS)

Figure 8: XRD scans of CFS and APS starting powders and related coatings, showing optimum match in phase composition.

of tetragonal/cubic structure (Fig. 8(b)). It is well-known in literature that $\sim 7-8 \% \mathrm{YSZ}$ can assume three wellknown structural forms: monoclinic, tetragonal and cubic depending on temperature and processing conditions 24. The presence of Yttria $\mathrm{Y}_{2} \mathrm{O}_{3}$ in this quantity $(\sim 7-8 \%)$ is added to $\mathrm{ZrO}_{2}$ in order to stabilize the tetragonal phase at ambient conditions (also named metastable tetragonal phase, $t^{\prime}$ ). Previous work on APS deposition of $\sim 7-8 \%$ YSZ materials performed by Ilavsky [25] reports how a separation between tetragonal and cubic phases by XRD analysis of initial feedstock powders is made difficult by the overlap of diffraction peaks in most of the range, suggesting the usage of alternative identification techniques for the same. Being not in scope for the current study, a subdivision between the two phases was not performed and both phases are reported in the legend of Fig. 8b. The compliance in phase transformations induced by CFS and APS deposition methods is also observed for the topcoat powders, as clearly shown by the affinity of XRD scans for coatings CFS_TR_E4 and APS_TC. Both layers show in fact a fully tetragonal structure and complete absence of monoclinic phase. This finding, not novel for APS-deposited $\sim 7-8 \%$ YSZ materials [25, 26], is for the first time reported in this work also for the case of CFS-deposited layers.

Figure 9 compares the average lifetime data measured for APS- and CFS-deposited specimens, normalised to the APS result. The coating lifetime was defined as cycling time to $>50 \%$ topcoat delamination. Six specimens per (APS - CFS) technique were tested, and corresponding standard deviations are shown in the graph. Results show 


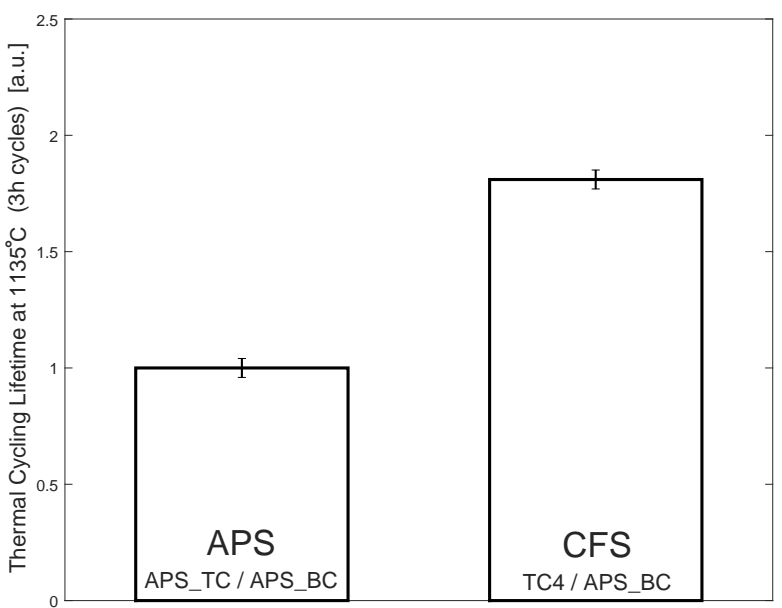

Figure 9: Average lifetime (total time to failure normalised to APS result) for APS- and CFS-deposited specimens. Note that APSsprayed APS_BC was employed as bondcoat in both cases. Standard deviations are calculated over 6 specimens prepared at the same conditions for each deposition technique.

that the lifetime reported for CFS-deposited specimens is higher than APS. Since in both cases the bondcoat layer was APS-deposited at the conditions of APS_BC, the observed difference is only attributed to the topcoat. During thermal loading, cracks are generated both within the topcoat and at the topcoat-bondcoat interface, due to both tensile and compressive strains caused by thermal expansion coefficient mismatch between the different layer materials and growth of Thermally Grown Oxide (TGO) [27, 28]. The higher density of porosity and intersplat cracks observed in the CFS-deposited TC4 specimen compared to APS_TC would suggest a superior tolerance to strain formation in the former case (Fig. 6). In other words, the CFS-deposited topcoat would redistribute thermal cycling strains more efficiently than the APS-produced one, with the consequence that more cycles are needed in order to build a sufficient stress for local crack propagation to occur. A detailed on-going microstructural analysis of the delaminated specimens will enable an accurate correlation between failure mechanisms and durability of TBC.

\section{Conclusions}

An in-depth study, to understand how the operating parameters of Combustion Flame Spray (CFS) influence the microstructure, microhardness and compositional phase changes has been performed on CoNiCrAlY and $\sim 7-$ $8 \%$ YSZ coatings that are extensively used as thermal barriers for aerospace applications. The effect of variation in deposition parameters, e.g. powder morphology, standoff distance, combustion and carrier gases flows, fuel-tooxygen equivalence ratio and powder feed rate have been assessed and a "close-to-optimal" set of deposition conditions was defined against measured thickness, porosity, oxide content and Knoop microhardness. SEM micrographs and X-ray diffraction of as-sprayed coatings were finally compared to standard systems deposited through Atmospheric Plasma Spray (APS), showing considerable similarities. In particular, the present research has highlighted the following key findings:

- Due to intrinsic lower flame temperature and combustion gases mass flow in CFS deposition compared to APS, a longer in-flight dwell time $\tau$ (2 compared to $0.9 \mathrm{~ms}$ respectively) and lower heat transferred $Q_{\text {int }}$ (0.2 compared to $4.0 \mathrm{~W}$ respectively) have been calculated. Consequently, powders of smaller size are needed in this former case to minimise the heat $Q_{M}$ necessary to melt the particles and obtain comparable microstructural properties in coatings sprayed by the two methods. Thus, by using powders with sizes $\sim 50$ $\%$ (CoNiCrAlY) and $\sim 40 \%(\sim 7-8 \%$ YSZ $)$ smaller in CFS compared to APS has been proven to reduce $Q_{M}$ of $\sim 85 \%$,

- Both CFS and APS deposition techniques have been proven to produce CoNiCrAlY and $\sim 7-8 \%$ YSZ coatings with missing $\beta-N i A l$ and monoclinic-cubic phases respectively, despite the same were detected in the initial powders. This demonstrates similarities in the chemical modifications induced by the two techniques,

- A general higher level of porosity $(+5 \%)$ and oxide strings content $(+67 \%)$, together with a decreased microhardness $(-10 \%)$ has been measured in CFS coatings compared to APS ones, even at the best deposition conditions tested in this study, highlighting the necessity of further in-depth process parameters optimisations,

- A $80 \%$ increase in thermal cycling lifetime has been measured in CFS- compared to APS-deposited TBC, likely linked to the higher strain tolerance of the former coatings.

The CFS technology has thus been proven to have the capability to produce coatings of quality comparable to APS systems by an accurate adjustment of deposition parameters. Thus, due to a considerable hardware simplicity of the former technique as compared to the latter, a new economically viable route together with the possibility to produce torches with miniaturised designs for deposition in confined environments has been uncovered.

\section{Acknowledgments}

The authors would like to thank the Swiss Federal Laboratories for Materials Testing and Research, Laboratory for Mechanics of Materials and Nanostructures (EMPA) for providing access to investigatory equipment and $\mathrm{Mr}$. R. Screaton of University of Nottingham for support on setting up the deposition hardware. The work has been supported by EPSRC UK (EP/L505572/1) under a RollsRoyce CASE award scheme. 


\section{References}

[1] N. P. Padture, M. Gell, E. H. Jordan, Thermal Barrier Coating for Gas-Turbine Engine Applications, Science 296 (2002) 280284.

[2] L. Fauchais, J. Heberlein, M. Boulos, Thermal Spray Fundamentals: From Powder to Part, Springer, 2014.

[3] F. Savkar, P. Siemers, Some recent developments in rapid solidification plasma deposition technology, Boulos, M. (ed) Workshop applications, 1989, pp. 80-89.

[4] P. Richer, M. Yandouzi, L. Beauvais, B. Jodoin, Oxidation behaviour of conicraly bond coats produced by plasma, hvof and cold gas dynamic spraying, Surface and Coatings Technology 204 (2010) 3962-3974.

[5] W. R. Chen, X. Wu, B. R. Marple, P. C. Patnaik, TGO growth behaviour in TBCs with APS and HVOF bond coats, Surface and Coatings Technology 202 (2008) 2677-2683.

[6] T. Patterson, A. Leon, B. Jayaraj, J. Liu, Y. H. Sohn, Thermal cyclic lifetime and oxidation behavior of air plasma sprayed CoNiCrAlY bond coats for thermal barrier coatings, Surface and Coatings Technology 203 (2008) 437-441.

[7] M. Friis, C. Persson, J. Wigren, Influence of particle in-flight characteristics on the microstructure of atmospheric plasma sprayed yttria stabilized $\mathrm{ZrO} 2$, Surface and Coatings Technology 141 (2-3) (2001) 115-127.

[8] Thermal Spraying Practice, Theory and Application, American Welding Society, 1985.

[9] A. D. Hewitt, Technology of Oxy-Fuel gas processes. part2: Comparative combustion properties of fuel gases, Welding and Metal Fabrication (1972) 382-389.

[10] M. W. Riley, New flame sprayed ceramics, Materials Methods 42 (1955) 96-98.

[11] N. N. Ault, Characteristics of refractory oxide coatings produced by flame spraying, Journal of the American Ceramic Society 140 (1957) 69-74.

[12] S. G. Grisaffe, Simplified guide to thermal-spray coatings, Mach. Des. 39 (1967) 174-181.

[13] C. Cano, M. Osendi, M. Belmonte, P. Miranzo, Effect of the type of flame on the microstructure of CaZrO3 combustion flame sprayed coatings, Surface and Coatings Technology 201 (6) (2006) 3307-3313.

[14] A. Gonzalez, J. Henao, E. Felipe Diaz, A. Lopez, F. Vargas, Influencia de los parmetros de proyeccin trmica en la microestructura de los recubrimientos de circona-almina y circonaceria usados como barreras trmicas, Rev. LatinAm. Metal. Mat.

[15] Y.-M. Yang, H. Liao, C. Coddet, Simulation and application of a hvof process for mcraly thermal spraying, Journal of Thermal Spray Technology 11 (2002) 36-43.

[16] K. Remesh, H. W. Ng, S. C. M. Yu, Influence of process parameters on the deposition footprint in plasma-spray coatings, Journal of Thermal Spray Technology 12(3) (2003) 377-392.

[17] M. Vardelle, A. Vardelle, A. Denoirjean, P. Fauchais, Heat treatment of zirconia powders with different morphologies under thermal plasma conditions, Mat. Res. Soc. Symp. Proc. (MRS) 190 (1991) 175-183.

[18] F. Ben-Ettouil, F. Mazhorovaa, B. Pateyron, H. Ageorges, M. El-Ganaoui, P. Fauchais, Predicting dynamic and thermal histories of agglomerated particles injected within a d.c. plasma jet, Surface and Coatings Technology 202 (2008) 4491-4495.

[19] T. Streibl, A. Vaidya, M. Friis, V. Srinivasan, S. Sampath, A critical assessment of particle temperature distributions during plasma spraying: Experimental results for ysz, Plasma Chemistry and Plasma Processing 26 (2006) 73-102.

[20] R. Bandyopadhyay, P. Nylen, A computational fluid dynamic analysis of gas and particle flow in flame spraying, Journal of Thermal Spray Technology 12 (2003) 492-503.

[21] H.-B. Xiong, L.-L. Zheng, L. Li, A. Vaidya, Melting and oxidation behavior of in-flight particles in plasma spray process, International Journal of Heat and Mass Transfer 48 (2005) 51215133.

[22] S. Kuroda, T. W. Clyne, The quenching stress in thermally sprayed coatings, Thin Solid Films 200 (1991) 49-66.
[23] M. Di Ferdinando, A. Fossati, A. Lavacchi, U. Bardi, F. Borgioli, C. Borri, C. Giolli, A. Scrivani, Isothermal oxidation resistance comparison between air plasma sprayed, vacuum plasma sprayed and high velocity oxygen fuel sprayed CoNiCrAlY bond coats, Surface and Coatings Technology 204 (2010) 2499-2503.

[24] B. Basu, Toughening of yttria-stabilised tetragonal zirconia ceramics, International Materials Reviews 50 (2005) 239-256.

[25] J. Ilavsky, J. K. Stalick, Phase composition and its changes during annealing of plasma-sprayed YSZ, Surface and Coatings Technology 127 (1999) 120-129.

[26] R. W. Trice, Y. J. Su, J. R. Mawdsley, K. T. Faber, A. R. De Arellano-Lopez, H. W. Wang, W. D. Porter, Effect of heat treatment on phase stability, microstructure, and thermal conductivity of plasma sprayed YSZ, Journal of Materials Science 37 (2002) 2359-2365.

[27] J. Voyer, F. Gitzhofer, M. I. Boulos, Study of the performance of tbc under thermal cycling conditions using an acoustic emission rig, Journal of Thermal Spray Technology 7 (1998) 181-190.

[28] M. Martena, D. Botto, P. Fino, S. Sabbadini, M. M. Gola, C. Badini, Modelling of TBC system failure: Stress distribution as a function of TGO thickness and thermal expansion mismatch, Engineering Failure Analysis 13 (2006) 409-426. 